\title{
Occipital sources of resting-state alpha rhythms are related to local gray matter density in subjects with amnesic mild cognitive impairment and Alzheimer's disease
}

\author{
Claudio Babiloni ${ }^{\mathrm{a}, \mathrm{b}, *}$, Claudio Del Percio $^{\mathrm{b}}$, Marina Boccardi ${ }^{\mathrm{c}}$, Roberta Lizio ${ }^{\mathrm{b}}$, \\ Susanna Lopez ${ }^{a}$, Filippo Carducci ${ }^{a}$, Nicola Marzano ${ }^{\mathrm{d}}$, Andrea Soricelli ${ }^{\mathrm{d}, \mathrm{e}}$, Raffaele Ferri ${ }^{\mathrm{f}}$, \\ Antonio Ivano Triggiani ${ }^{\mathrm{g}}$, Annapaola Prestia ${ }^{\mathrm{c}}$, Serenella Salinari ${ }^{\mathrm{h}}$, Paul E. Rasser ${ }^{\mathrm{i}, \mathrm{j}}$, \\ Erol Basar ${ }^{k}$, Francesco Famà ${ }^{1}$, Flavio Nobili ${ }^{1}$, Görsev Yener ${ }^{\mathrm{k}, \mathrm{m}, \mathrm{n}, \mathrm{o}}$, \\ Derya Durusu Emek-Savaş $^{\mathrm{k}, \mathrm{m}}$, Loreto Gesualdo $^{\mathrm{p}}$, Ciro Mundi ${ }^{\mathrm{q}}$, Paul M. Thompson ${ }^{\mathrm{r}}$, \\ Paolo M. Rossini ${ }^{\text {b,s }}$, Giovanni B. Frisoni ${ }^{c}$ \\ a Department of Physiology and Pharmacology, University of Rome “La Sapienza”, Rome, Italy \\ ${ }^{\mathrm{b}}$ Department of Neuroscience, IRCCS San Raffaele Pisana, Rome, Italy \\ ${ }^{c}$ LENITEM (Laboratory of Epidemiology, Neuroimaging and Telemedicine), IRCCS Centro “S. Giovanni di Dio-F.B.F.", Brescia, Italy \\ ${ }^{\mathrm{d}}$ Department of Integrated Imaging, IRCCS SDN, Napoli, Italy \\ e Department of Studies of Institutions and Territorial Systems, University of Naples Parthenope, Naples, Italy \\ ${ }^{\mathrm{f}}$ Department of Neurology, IRCCS Oasi Institute for Research on Mental Retardation and Brain Aging, Troina, Enna, Italy \\ ${ }^{g}$ Department of Clinical and Experimental Medicine, University of Foggia, Foggia, Italy \\ h Department of Informatics and Systems "Antonio Ruberti", University of Rome "La Sapienza", Rome, Italy \\ ${ }^{\mathrm{i}}$ Centre for Translational Neuroscience \& Mental Health Research, The University of Newcastle, Newcastle, New South Wales, Australia \\ ${ }^{j}$ Schizophrenia Research Institute, Darlinghurst, New South Wales, Australia \\ ${ }^{\mathrm{k}}$ Brain Dynamics, Cognition and Complex Systems Research Center, Istanbul Kültür University, Istanbul, Turkey \\ ${ }^{1}$ Department of Neuroscience (DINOGMI), Clinical Neurology, University of Genoa, Italy \\ ${ }^{\mathrm{m}}$ Department of Neurosciences, Dokuz Eylül University, Izmir, Turkey \\ ${ }^{n}$ Brain Dynamics Multidisciplinary Research Center, Dokuz Eylül University, Izmir, Turkey \\ ${ }^{\circ}$ Department of Neurology, Dokuz Eylül University Medical School, Izmir, Turkey \\ ${ }^{\mathrm{p}}$ Dipartimento Emergenza e Trapianti d'Organi (D.E.T.O), University of Bari, Bari, Italy \\ ${ }^{\mathrm{q}}$ Department of Neurology, Ospedali Riuniti, Foggia, Italy \\ ${ }^{r}$ Department of Neurology \&' Psychiatry, Imaging Genetics Center, Laboratory of Neuro Imaging, UCLA School of Medicine, Los Angeles, CA, USA \\ ${ }^{s}$ Department of Geriatrics, Neuroscience \& Orthopedics, Institute of Neurology, Catholic University, Rome, Italy
}

\section{A R T I C L E I N F O}

\section{Article history:}

Received 9 July 2012

Received in revised form

8 September 2014

Accepted 10 September 2014

Available online 21 September 2014

Keywords:

Mild cognitive impairment (MCI)

Alzheimer's disease (AD)

Electroencephalography (EEG)

Magnetic resonance imaging (MRI)

Gray matter density (GMD)

\begin{abstract}
A B S T R A C T
Occipital sources of resting-state electroencephalographic (EEG) alpha rhythms are abnormal, at the group level, in patients with amnesic mild cognitive impairment (MCI) and Alzheimer's disease (AD). Here, we evaluated the hypothesis that amplitude of these occipital sources is related to neurodegeneration in occipital lobe as measured by magnetic resonance imaging. Resting-state eyes-closed EEG rhythms were recorded in 45 healthy elderly (Nold), $100 \mathrm{MCI}$, and $90 \mathrm{AD}$ subjects. Neurodegeneration of occipital lobe was indexed by weighted averages of gray matter density, estimated from structural MRIs. EEG rhythms of interest were alpha $1(8-10.5 \mathrm{~Hz})$ and alpha $2(10.5-13 \mathrm{~Hz})$. EEG cortical sources were estimated by low-resolution brain electromagnetic tomography. Results showed a positive correlation between occipital gray matter density and amplitude of occipital alpha 1 sources in Nold, $\mathrm{MCI}$, and $\mathrm{AD}$ subjects as a whole group $(\mathrm{r}=0.3, p=0.000004, \mathrm{~N}=235)$. Furthermore, there was a positive correlation between the amplitude of occipital alpha 1 sources and cognitive status as revealed by Mini Mental State Examination score across all subjects $(r=0.38, p=0.000001, \mathrm{~N}=235)$. Finally, amplitude of occipital alpha 1 sources allowed a moderate classification of individual Nold and $A D$ subjects (sensitivity: $87.8 \%$; specificity: 66.7\%; area under the receiver operating characteristic curve:
\end{abstract}

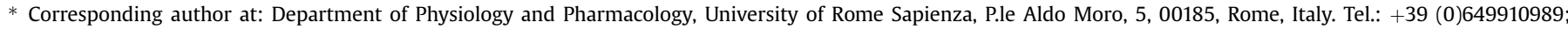
fax: +39 (0)649910917.

E-mail address: claudio.babiloni@uniroma1.it (C. Babiloni).
} 
0.81). These results suggest that the amplitude of occipital sources of resting-state alpha rhythms is related to $\mathrm{AD}$ neurodegeneration in occipital lobe along pathologic aging.

(c) 2015 Elsevier Inc. All rights reserved.

\section{Introduction}

Amnesic mild cognitive impairment (MCI) is a clinically intermediate state between elderly normal cognition and Alzheimer's disease (AD). MCI subjects show memory complaints and cognitive impairment on neuropsychological tests but do not yet fulfill the clinical criteria for dementia (Flicker et al., 1991; Petersen et al., 1995, 2001). MCI may be considered as a precursor to AD (Arnaiz and Almkvist, 2003; Galluzzi et al., 2001; Scheltens et al., 2002), given the high rate of progression from $\mathrm{MCI}$ to $\mathrm{AD}$ (Bachman et al., 1993; Gao et al., 1998; Petersen et al., 2001). In cognitively intact elderly subjects, the annual rate of transition to $\mathrm{AD}$ ranges from 0.17\% to 3.86\% (Frisoni et al., 2004; Petersen et al., 2001), but it is much higher in patients with $\mathrm{MCI}$, ranging from $6 \%$ to $25 \%$ (Petersen et al., 2001). However, the "transition" hypothesis is challenged by the fact that not all $\mathrm{MCI}$ subjects deteriorate over time (Bennett et al., 2002; Larrieu et al., 2002), as cumulative incidence rates for AD range from $40 \%$ to $60 \%$ after about 5 years (Bennett et al., 2002; Fisk et al., 2003; Larrieu et al., 2002).

Neuropsychological markers are extremely important for the assessment of prodromal stages of $A D$, but there is consensus that a crucial challenge of aging research is a better understanding of the neurobiological basis of the MCI condition, to refine diagnostic procedures and to target new pharmacologic interventions (Albert et al., 2011; Braak and Braak, 1991; Dubois et al., 2007; Nestor et al., 2004; Rogers et al., 1996; Small et al., 1995). In the light of the new international guidelines (Albert et al., 2011; Dubois et al., 2007), prodromal stages of $\mathrm{AD}$ in $\mathrm{MCI}$ subjects can be diagnosed by abnormal dosages of the "A beta amyloid to tau" ratio in cerebrospinal fluid (CSF) and deposition of A beta amyloid in the brain, as revealed by ligand-based positron emission tomography (PET). Other useful biomarkers are overt signs of neurodegeneration such as atrophy of the hippocampus, on magnetic resonance imaging (MRI), or hypometabolism of the posterior cingulate and/or precuneus, parietal, and temporal regions, as revealed by fluorodeoxyglucose positron emission tomography (Albert et al., 2011; Dubois et al., 2007). However, CSF and PET markers are invasive, and MRI markers of hippocampus volume are relatively expensive for serial screening of large elderly populations at risk of AD. For this reason, other fully noninvasive and more cost-effective procedures have been investigated in the past years.

A promising approach to assess $\mathrm{MCI}$ subjects is the recording of resting-state eyes-closed electroencephalographic (EEG) rhythms. This approach is based on low cost and relatively widely available equipment, as well as being is noninvasive. It can also be used to collect serial measurements without incurring misleading effects that are solely because of the repetition of the procedure (Rossini et al., 2007). Prior studies have successfully investigated the resting-state eyes-closed EEG rhythms in $\mathrm{MCI}$ and AD subjects. Compared with normal elderly subjects (Nold), AD patients showed an increase in delta (1-4 Hz) rhythms, and a decrement of posterior alpha $(8-12 \mathrm{~Hz})$ rhythms (Dierks et al., 2000, 1993; Huang et al., 2000; Jeong, 2004; Ponomareva et al., 2003; Koenig et al., 2005). These EEG abnormalities are associated with altered regional cerebral blood flow and/or metabolism and with impaired global cognitive function as evaluated by the mini mental state examination (MMSE; Jeong, 2004; Rodriguez et al., 1998, 1999a, 1999b; Sloan et al., 1995). Similarly, MCI subjects show a decrease of alpha rhythms compared with normal elderly subjects (Elmstahl and Rosen, 1997; Huang et al., 2000; Jelic et al., 2000; Koenig et al., 2005; Zappoli et al., 1995). However, a certain variability of the brain rhythms in pathologic aging might prevent its use for personalized diagnosis and prognosis, especially in early $\mathrm{MCl}$. For example, recent magnetoencephalographic evidence has not detected a statistically significant difference in brain rhythms in Nold and MCI subjects (Osipova et al., 2006).

When assessing MCI and AD subjects, the practical use of EEG markers would require preliminary validation studies showing that these markers are clearly related to $\mathrm{AD}$ neurodegenerative processes as revealed by brain atrophy. In this vein, it has been shown that EEG and structural MRI data complement each other in the modeling of psychomotor speed, global cognition, memory, and language ability in pathologic aging (Strijers et al., 1997). Brain atrophy has been proposed as the primary factor associated with psychomotor speed on the "trail making" test, but variations of alpha rhythms have been associated with a wider range of cognitive functions (Van der Hiele et al., 2007). Furthermore, $\mathrm{MCl}$ subjects with different degrees of hippocampal atrophy were characterized by different amplitude of the resting-state EEG rhythms, especially at dominant alpha frequencies (Moretti et al. 2007, 2011).

A step forward in studying the relationship between restingstate EEG rhythms and structural MRI markers of AD neurodegeneration would be the use of EEG and MRI markers, with data co-registered in the same anatomic space. For this purpose, a promising approach is the estimation of the cortical sources of the resting-state EEG rhythms by low-resolution brain electromagnetic tomography (LORETA), (Pascual-Marqui and Michel, 1994; PascualMarqui et al., 1999; 2002). For this kind of analysis, software is freely available and has been successfully used in cognitively impaired elderly subjects (Caso et al., 2012; Nishida et al., 2011). With this goal in mind, our research group has repeatedly used LORETA methods to study the cortical sources of the resting-state EEG rhythms in $\mathrm{MCI}$ and $\mathrm{AD}$ subjects. In these studies, occipital sources of the resting-state alpha rhythms were the most promising EEG markers of prodromal AD in MCI subjects. Specifically, the magnitude of occipital sources of alpha rhythms was positively correlated with the score on the MMSE and attention tasks in $\mathrm{MCl}$ and AD subjects (Babiloni et al., 2006a, 2007). Furthermore, it was negatively related to the atrophy of the hippocampal and global cortical gray matter as measured by structural MRIs in MCI and AD subjects (Babiloni et al., 2009a, 2013).

Keeping in mind the previously mentioned data, the present study investigated the relationship between neurodegeneration in the occipital lobe, occipital sources of alpha rhythms, and global cognitive status in Nold, $\mathrm{MCI}$, and AD subjects. We hypothesized that the higher the neurodegeneration in the occipital lobe, the lower the amplitude of occipital sources of alpha rhythms and the lower the global cognitive status. To this aim, resting-state eyesclosed EEG rhythms were recorded in Nold, MCI, and AD subjects. Cortical sources of these EEG rhythms were estimated using the LORETA software. The MMSE score was used to index the global cognitive status (Folstein et al., 1975). Neurodegeneration of the occipital lobe was indexed by gray matter density (GMD) estimated from the subject's MRI, with GMD considered a good index of regional atrophy provoked by neuronal loss (Kassubek et al., 2004; Mummery et al., 2000). 


\section{Methods}

We have extensively described in recent articles on EEG and pathologic aging the methodological approach (e.g., procedures of subjects recruitment, EEG recordings, estimation of the cortical sources of resting-state EEG rhythms, and statistical design) used in the present study (Babiloni et al., 2006a, 2006b, 2006c; 2007, 2009a, 2009b, 2013). As a novelty, this is the first study to test the hypothesis that the abnormality of alpha rhythms in the occipital sources is specifically related to the neurodegeneration in the occipital lobe as revealed by MRI. The present results may also be compared with previous studies from our research group using the same basic methodology (Babiloni et al., 2006a, 2006b, 2006c, 2007, 2009a, 2009b, 2013).

\subsection{Subjects and diagnostic criteria}

Forty-five cognitively normal elderly (Nold), 100 amnesic $\mathrm{MCI}$, and $90 \mathrm{AD}$ subjects were enrolled by the following clinical centers: Isola Tiberina Fatebenefratelli Hospital of Rome (Italy), IRCCS Fatebenefratelli of Brescia (Italy), IRCCS SDN of Naples (Italy), United Hospital of University of Foggia (Italy), IRCCS Oasi of Troina (Italy), Service of Neurophysiopathology of the University of Genova (Italy), and Brain Dynamics Multidisciplinary Research Center, Dokuz Eylül University of Izmir (Turkey).

Local institutional ethics committees approved the study. All experiments were performed with the informed and overt consent of each participant or caregiver, in line with the Code of Ethics of the World Medical Association (Declaration of Helsinki) and the standards established by the local Institutional Review Board.

The present inclusion and exclusion criteria for $\mathrm{MCI}$ were based on previous seminal reports (Albert et al., 1991; Devanand et al., 1997; Flicker et al., 1991; Petersen et al., 1995, 1997, 2001; Portet et al., 2006; Rubin et al., 1989; Zaudig, 1992). Summarizing, the inclusion criteria were as follows: (1) objective memory impairment on neuropsychological evaluation as defined by performances $\geq 1.5$ standard deviations below the mean value for age and education-matched controls for a neuropsychological test battery of neuropsychological tests, to assess cognitive performance in the domains of memory (i.e., Busckhe-Fuld and Memory Rey tests), language, executive function and/or attention, and visuoconstruction; (2) normal activities of daily living as documented by the history and evidence of independent living; and (3) clinical dementia rating score of 0.5 . The exclusion criteria included the following: (1) mild $\mathrm{AD}$, as diagnosed by standard protocols including NINCDS-ADRDA (McKhann et al., 1984); (2) evidence (including diagnostic MRI procedures) of concomitant dementia such as frontotemporal, vascular dementia, reversible dementias (including pseudo-depressive dementia), marked fluctuations in cognitive performance compatible with Lewy body dementia and/ or features of mixed dementias; (3) evidence of concomitant extrapyramidal symptoms; (4) clinical and indirect evidence of depression as revealed by Geriatric Depression Scale scores higher than 13; (5) other psychiatric diseases, epilepsy, drug addiction, alcohol dependence (as revealed by a psychiatric interview) or use of psychoactive drugs including acetylcholinesterase inhibitors or other drugs enhancing cognitive functions; and (6) current or previous uncontrolled or complicated systemic diseases (including diabetes mellitus) or traumatic brain injuries. Of note, benzodiazepines, antidepressant and/or antihypertensive drugs when present were withdrawn for about 24 hours before the EEG recordings, to equalize the period from the last use of the drugs until the EEG recordings across the subjects within the $\mathrm{MCI}$ and $\mathrm{AD}$ groups.

A battery of neuropsychological tests were performed to assess general cognitive performance in the domains of memory, language, executive function and/or attention, and visuoconstruction abilities, in line with general international standards of AD research. In some cases, different tests were used by different clinical centers to probe a given cognitive function, as the original data collection in those centers was not specifically done in the framework of the present multicentric study. The tests assessing memory were the immediate and the delayed recall measure of the Rey Auditory Verbal Learning Test (Carlesimo, 1996; Rey, 1958), the delayed recall of Rey figures (Rey, 1968), the delayed recall of a 3words list (Chandler et al., 2004), and the delayed recall of a story (Spinnler and Tognoni, 1987). The tests assessing language were the 1-minute verbal fluency for letters (Novelli, 1986), the 1-minute verbal fluency for fruits, animals, or car trades (Novelli, 1986), and the Token test (De Renzi and Vignolo, 1962; Spinnler and Tognoni, 1987). The tests assessing executive function and attention were the Trail Making Test part A and B (Reitan, 1958) and the Digit forward and Digit backward tasks (Orsini et al., 1987). Finally, the tests assessing visuoconstruction were the copy of Rey figures (Rey, 1968), the Raven Progressive matrices (Raven, 1965), and the Clock Drawing test (Shulman et al., 1993).

Probable AD was diagnosed according to the NINCDS-ADRDA (McKhann et al., 1984) and the DSM-IV criteria. The recruited AD patients underwent general medical, neurologic, and psychiatric assessments. Patients were also rated with a number of standardized diagnostic and severity instruments that included the MMSE (Folstein et al., 1975), Clinical Dementia Rating Scale (Hughes et al., 1982), Geriatric Depression Scale (Yesavage et al., 1982-1983), Hachinski Ischemic Score (Rosen et al., 1980), and Instrumental Activities of Daily Living scale (Lawton and Brodie, 1969). Neuroimaging diagnostic procedures from MRI and complete laboratory analyses were carried out to exclude other causes of progressive or reversible dementias to have a clinically homogenous mild $\mathrm{AD}$ patient group. Exclusion criteria included, in particular, any evidence of (1) frontotemporal dementia, diagnosed according to criteria of Lund and Manchester Groups (1994); (2) vascular dementia, diagnosed according to NINDS-AIREN criteria (Roman et al., 1993), (3) extra-pyramidal syndromes; (4) reversible dementias (including depressive pseudodementia syndrome); and (5) Lewy body dementia, according to the criteria by McKeith et al. (1999).

Nold subjects were often recruited among nonconsanguineous patients' relatives. All Nold subjects underwent physical and neurologic examinations as well as cognitive screening. Subjects affected by chronic systemic illnesses, those receiving psychoactive drugs, or with a history of neurologic or psychiatric disease were excluded. Also, Nold subjects did not suffer from clinical depression (i.e., Geriatric Depression Scale score lower than 14 or scores indicating no depression by other equivalent clinical scales).

\subsection{MRI scans and gray matter density}

Proton density, T1- and T2-weighted structural MRIs were acquired following standard research settings mostly by $1.5 \mathrm{~T}$ scanners at the following clinical centers: Isola Tiberina Fatebenefratelli Hospital of Rome (Italy); IRCCS Fatebenefratelli of Brescia (Italy); IRCCS SDN of Naples (Italy); United Hospital of University of Foggia (Italy); IRCCS Oasi of Troina (Italy); Service of Neurophysiopathology of the University of Genova (Italy); and Brain Dynamics Multidisciplinary Research Center, Dokuz Eylül University of Izmir (Turkey). Some of these units (IRCCS SDN of Naples; United Hospital of University of Foggia; IRCCS Oasi of Troina; and Service of Neurophysiopathology of the University of Genova) collected the MRIs following the ADNI protocol (http://www.adniinfo.org/).

The MRI scans were visually inspected to verify the absence of structural abnormalities or technical artifacts. MRI data analysis 
was performed using Functional Magnetic Resonance Imaging of the Brain (FMRIB) Software Library (FSL) to evaluate GMD. Here, GMD was defined as the probability of a brain voxel belonging to gray matter (GM) on the basis of the amount of surrounding GM voxels. Specifically, the probability belonging to GM was estimated by the following procedure. First, an atlas-based parcellation procedure was performed by the FSL-BET tool to automatically extract a subject's brain region from their MRI. This was followed by a single-channel segmentation using the FAST tool of FSL, producing a posterior probability maps in the individual subject's space for $\mathrm{GM}$, white matter, and CSF with each voxel in the range $0-1$, where 1 represent the maximum probability (Zhang et al., 2001). Specifically, the FAST tool is based on a hidden Markov random field (HMRF) model and an associated expectation maximization algorithm (Zhang et al., 2001). The advantage of the HMRF model derives from the way in which the MRI spatial information is encoded through the mutual influences of neighboring voxels causing spatial regularization and reducing the effect of noise on the segmentation. According to the present procedure, the HMRF model is fitted by an expectation maximization algorithm to achieve an accurate and robust segmentation (Zhang et al., 2001). Third, GM probability maps were nonlinearly normalized (FSL-FNIRT tool) to fit a standard labeled template. This resulted in an associated spatial transformation matrix from subject space to standard template space. The template was based on averaged high-resolution MRIs acquired from 24 subjects, comprising anatomic channels (T1, T2, and proton density weighted), tissue channels (CSF probability, GM probability, white matter probability, and tissue labels), and 2 cortical parcellation maps, namely the TZO map, based on the template by Tzourio-Mazoyer et al. (2002), and the LPBA40 map, based on the LONI Probabilistic Brain Atlas of 40 subjects (Shattuck et al., 2008). Fourth, we focused on GM probability maps of cortical regions of interest (ROIs). Left and right brain occipital lobes were the experimental ROIs, whereas left and right temporal ROIs were the control ROIs. These ROIs were extracted from MRIs as binary masks, on the basis of LPBA40 map, because FNIRT tool has shown a high relative accuracy for this parcellation map. Then, ROIs masks were mapped in subject's space using the inverse transformation matrix previously obtained. These mapped ROIs masks were used to obtain GMD values of all voxels belonging to left and right occipital and temporal lobes from the original GM probability maps. Finally, GMD within the occipital lobe was obtained by averaging the GMD values of all voxels within that lobe (Pizzagalli et al., 2004). The same procedure was true for the temporal lobe.

\subsection{EEG recordings}

In the present study, the resting-state condition is defined as a mode of brain activity unrelated to visual information processing, prolonged specific tasks, or goal-oriented cognitive operations (e.g., oriented thinking, problem solving, expectancy, planning daily activities, and so forth). In this resting-state mode, there is a fluctuation of cortical arousal, alertness, and contents of mental operations along the EEG recording session. The subjects received the instruction to close their eyes, not to sleep, and not to engage in any persistent or specific goal-oriented cognitive activity (e.g., see the previously mentioned data).

Resting-state eyes-closed EEG data were recorded from the Nold, $\mathrm{MCI}$, and $\mathrm{AD}$ subjects by specialized clinical units, during the diagnostic phase. EEG recordings were carried out $(0.3-70 \mathrm{~Hz}$ bandpass; cephalic reference) from 19 electrodes positioned according to the international 10-20 system (i.e., Fp1, Fp2, F7, F3, Fz, F4, F8, T3, C3, Cz, C4, T4, T5, P3, Pz, P4, T6, O1, O2; cephalic reference, and ground). To monitor eye movements, bipolar horizontal and vertical electrooculogram (EOG, $0.3-70 \mathrm{~Hz}$ bandpass) was also collected. All data were digitized in continuous recording mode (5 minutes of EEG; $128-256 \mathrm{~Hz}$ sampling rate). All EEG recordings were performed in the late morning. To keep the level of vigilance constant, an experimenter monitored the subject and the EEG traces online in real time. In general, experimenter alerted the subject when behavior and/or posture indicated a possible trend toward sleep intrusion or slow-frequency EEG waves (this was then annotated into the report of EEG recording). Reports on EEG recordings were available in 2 subgroups of 19 Nold and 14 AD subjects. No Nold subject of the subgroup received an alert for a possible sleep intrusion. About $3 \%$ of the AD patients of the subgroup received such an alert. Median test ( $p<0.05$, one way) showed no statistically significant difference of that variable between the Nold and AD subgroups $(p>0.05)$. The mentioned reports also allowed an evaluation of further general aspects of EEG recordings. No subject asked for an interruption of the EEG recording session, reported problems adhering to the instructions or experienced untoward disturbances or noise during the experiment.

To further address the issue of patients' drowsiness, an off-line analysis of slow-frequency EEG waves was performed on all 235 subjects of the present study (45 Nold, $100 \mathrm{MCI}$, and $90 \mathrm{AD}$ ). The percentages of subjects showing the appearance of slow-frequency EEG waves were found to be $2.2 \%$ for the Nold group, $4 \%$ for the $\mathrm{MCI}$ group, and $4.4 \%$ for the AD group. A median test ( $p<0.05$, one way) showed no statistically significant difference among the Nold, MCI, and AD groups ( $p>0.05)$.

\subsection{Preliminary EEG-EOG data analysis}

The recorded EEG data were analyzed and fragmented off line in consecutive epochs of 2 seconds. EEG epochs with ocular, muscular, and other types of artifact were first identified by a computerized automatic procedure based on an amplitude threshold set at $100 \mu \mathrm{V}$. Mean percentages of EEG epochs with blinking artifacts were of $9.7 \%$ ( $\pm 2.6 \mathrm{SE}$ ) for the Nold group, of $11.3 \%$ ( $\pm 2 \mathrm{SE}$ ) for the $\mathrm{MCI}$ group, and of $14.2 \%$ ( $\pm 2.1 \mathrm{SE}$ ) for the AD group. An analysis of variance (ANOVA) with the factor group (Nold, MCI, and AD) was used to evaluate possible statistically significant differences of EEG epochs with blinking artifacts among the 3 groups $(p<0.05)$. No statistically significant difference among the groups was found $(F$ $[2,232]=0.4 ; p>0.05)$. EEG epochs with sporadic blinking artifacts were corrected by an autoregressive method (Moretti et al., 2003).

Two experimenters blind to subject diagnosis, performed the preliminary data analysis of all EEG epochs to reject artifactual EEG epochs not only related to uncorrected blinking and eye movements but also to head movements and EEG signs of drowsiness or presleep stages. As a result, they selected the following mean percentages of artifact-free EEG epochs: $81.7 \%( \pm 1.6 \mathrm{SE})$ for the Nold group, $82.3 \%$ ( $\pm 1.5 \mathrm{SE}$ ) for the $\mathrm{MCI}$ group, and $79 \%( \pm 1.6 \mathrm{SE})$ for the AD group. An ANOVA with the factor group (Nold, MCI, and AD) served to evaluate possible statistically significant differences among these mean values $(p<0.05)$. No statistically significant difference among the groups was found $(F[2,232]=1.8, p>0.05)$. Artifact-free EEG epochs were then re-referenced to common average for further analysis.

\subsection{Spectral analysis of the EEG data}

A digital Fast Fourier Transform-based power spectrum analysis (Welch technique, Hanning windowing function, and no phase shift) was used to compute the power density of the EEG rhythms with $0.5 \mathrm{~Hz}$ frequency resolution. The following standard band frequencies were studied: the standard frequency bands of interest 
were delta $(2-4 \mathrm{~Hz})$, theta $(4-8 \mathrm{~Hz})$, alpha $1(8-10.5 \mathrm{~Hz})$, alpha 2 $(10.5-13 \mathrm{~Hz})$, beta $1(13-20 \mathrm{~Hz})$, and beta $2(20-30 \mathrm{~Hz})$.

The choice of the fixed EEG bands did not account for the individual alpha frequency (IAF) peak, defined as the frequency associated with the strongest EEG power at the extended alpha range of $6-14 \mathrm{~Hz}$ (Klimesch, 1999). The mean IAF peak was of $9.6 \mathrm{~Hz}( \pm 0.1$ $\mathrm{SE})$ for the Nold group, of $9.2 \mathrm{~Hz}( \pm 0.1 \mathrm{SE})$ for the MCI group, and of $8.4 \mathrm{~Hz}( \pm 0.1 \mathrm{SE})$ for the AD group. An ANOVA $(p<0.05)$ with the factor Group (Nold, $\mathrm{MCI}$, and $\mathrm{AD}$; independent variable) was used to evaluate possible statistically significant differences of IAF peak among the 3 groups. A statistically significant difference was found $(F[2,232]=2.3, p<0.000001)$. Duncan post hoc testing $(p<0.05$, one way) indicated that IAF peak was higher in the Nold group compared with the $\mathrm{MCI}(p<0.05)$ and the $\operatorname{AD}$ group $(p<0.00001)$. IAF peak was also higher in the MCI than in the AD group ( $p<$ 0.00005 ). To control for the residual effect of IAF on the comparison of EEG variables, the IAF peak was used as a covariate in further EEG statistics.

\subsection{Cortical source of EEG rhythms as computed by LORETA}

LORETA, as provided at http://www.unizh.ch/keyinst/NewLORETA/ LORETA01.htm, was used to estimate cortical sources of EEG rhythms (Pascual-Marqui and Michel, 1994; Pascual-Marqui et al., 1999, 2002). LORETA is a functional imaging technique belonging to a family of linear inverse solution procedures (Valdès et al., 1998) modeling 3D distributions of EEG sources (Pascual-Marqui et al., 2002). With respect to the dipole modeling of cortical sources, no a priori decision of the dipole position is required by the LORETA procedure.

LORETA can be utilized from EEG data collected by low spatial sampling of 10-20 system (19 electrodes) when cortical sources are estimated from resting-state eyes-closed EEG rhythms. Furthermore, it should be noted that LORETA solutions are intrinsically maximally smoothed at source space, because of its regularization procedure (Pascual-Marqui and Michel, 1994), and prevents effects of spatial aliasing of the source solutions.

LORETA computes 3D linear solutions (LORETA solutions) for the EEG inverse problem within a 3-shell spherical head model including scalp, skull, and brain compartments. The brain compartment is restricted to the cortical gray matter and/or hippocampus of a head model co-registered to the Talairach probability brain atlas and digitized at the Brain Imaging Center of the Montreal Neurological Institute (Talairach and Tournoux, 1988). This compartment includes 2394 voxels (7 mm resolution), with each voxel containing an equivalent current dipole. Notably, EEG electrode positions were not co-registered to individual brain source models; unfortunately, the official LORETA package did not include software to do so, and we could not obtain the digitalization of the electrode position from our clinical units.

LORETA solutions consisted of voxel z-current density values that are able to estimate EEG spectral power density at scalp electrodes, being a reference-free method of EEG analysis, one obtains the same LORETA source distribution for EEG data referenced to any reference electrode including common average. A normalization of the data was obtained by normalizing the LORETA current density at each voxel with the power density averaged across all frequencies $(0.5-45 \mathrm{~Hz})$ and across all 2394 voxels of the brain volume. After normalization, the solutions lost the original physical dimension and were represented on an arbitrary unit scale. This procedure reduced inter-subject variability and was used in previous EEG studies. The general procedure fitted the LORETA solutions in a Gaussian distribution and reduced inter-subject variability. Other normalization methods using principal components analysis are effective for estimating the subjective global factor scale of the
EEG data (Hernández et al., 1994). These methods are not available in the LORETA package, so they were not used in this study.

Solutions of the EEG inverse problem are under determined and ill conditioned when the number of spatial samples (electrodes) is lower than that of the unknown samples (current density at each voxel). To address this, the cortical LORETA solutions predicting scalp EEG spectral power density were regularized to estimate distributed rather than punctual EEG source patterns. In line with the low spatial resolution of the adopted technique, we used our MATLAB software to collapse the voxels of LORETA solutions to the occipital region of the brain model coded into Talairach space. The Brodmann areas listed in Table 1 formed each of these ROIs.

Regional analysis of LORETA solutions has the advantage to disentangle alpha rhythms of occipital sources from those of the contiguous parietal and temporal sources. In contrast, the EEG potentials collected at each scalp electrode are strongly affected by head volume conductor effects. For example, occipital electrodes collect scalp potentials generated not only from the occipital cortex but also from parietal and temporal cortices because of well known head volume conductor effects. For this reason, the regional analysis of LORETA source solutions may represent an important reference for multimodal comparisons not only with structural neuroimaging, as in the present study, but also with functional neuroimaging (functional MRI, positron emission tomography, magnetoencephalography, and so forth).

In comparison with the estimation of the GMD in occipital lobe, the spatial localization of the LORETA solutions in the occipital sources is lower. The former was performed on the basis of individual MRIs whereas the latter was based on the MNI common average brain model and does not require the subject's electrode positions to be digitalized and co-registered to their individual MRI. This relatively low spatial resolution is acceptable when applied to the cortical source estimation of eyes-closed resting-state EEG rhythms as, in the resting-state condition, there is a widespread synchronization at dominant alpha frequencies of pyramidal neurons in occipital, parietal, and temporal cortical regions. This is opposed to the circumscribed desynchronization of these rhythms, especially at high frequencies, during the observation of visual or visuospatial stimuli. Moreover, the spatial resolution of the LORETA source solutions is intrinsically low for its peculiar maximally smoothing regularization procedure.

Currently, the official LORETA package does not support higher level co-registration between electrode position and MRIs, despite this, we continue to use this official release for our studies as it allows EEG research groups worldwide to extract the present EEG markers and replicate experimental findings. Nevertheless, we encourage the use of the individual MRIs for the LORETA source analysis in future validation studies using customized versions of the original LORETA program. The use of subjects' MRIs may allow a better localization of the LORETA occipital sources and a higher correlation between these sources and the occipital GMD in $\mathrm{MCI}$ and AD subjects. Such an advanced procedure might improve the clinical value of these EEG markers in $\mathrm{MCI}$ and $\mathrm{AD}$ patients.

\section{Table 1}

Brodmann areas included in the cortical regions of interest (ROIs) of the present study. LORETA solutions were collapsed in frontal, central, parietal, occipital, temporal, and limbic ROIs

LORETA Brodmann areas into the regions of interest (ROIs)

\begin{tabular}{ll} 
Frontal & $8,9,10,11,44,45,46,47$ \\
Central & $1,2,3,4,6$ \\
Parietal & $5,7,30,39,40,43$ \\
Temporal & $20,21,22,37,38,41,42$ \\
Occipital & $17,18,19$ \\
Limbic & $31,32,33,34,35,36$ \\
\hline
\end{tabular}




\subsection{Statistical analysis}

To test the working hypothesis, 3 main statistical sessions were performed by commercial tool STATISTICA (StatSoft Inc, www. statsoft.com).

First statistical session tested the control hypothesis that occipital GMD differs in amplitude among the Nold, MCI, and AD groups to validate the procedures of subjects' recruitment and MRI recording and analysis. To this aim, an ANOVA was computed using occipital GMD as a dependent variable $(p<0.05)$. ANOVA factor was group (Nold, MCI, AD; independent variable). Subjects' age, education, and gender were used as covariates. Mauchly test evaluated the sphericity assumption. Correction of the degrees of freedom was made with Greenhouse-Geisser procedure when appropriate. The Duncan test was used for post hoc comparisons $(p<0.05$, one way). The control hypothesis would be confirmed by the following 2 statistical results: (1) a statistical ANOVA effect including the factor group $(p<0.05)$; and (2) a post hoc test indicating statistically significant differences of occipital GMD with the pattern Nold $>\mathrm{MCI}>\mathrm{AD}$ (Duncan test; $p<0.05$, one way).

The second statistical session tested the control hypothesis that cortical (LORETA) sources of alpha rhythms differ in amplitude among the Nold, MCI, and AD groups. If confirmed, this would validate the procedures relative to subjects' recruitment and EEG data. To this aim, an ANOVA was computed using regional normalized LORETA solutions (normalized current density at all voxels of a given ROI) as a dependent variable $(p<0.05)$. The ANOVA factors were group (Nold, $\mathrm{MCI}$, and $\mathrm{AD}$; independent variable), band (delta, theta, alpha 1, alpha 2, beta 1 , and beta 2 ), and ROI (central, frontal, parietal, occipital, temporal, and limbic). Subjects' age, education, gender, and IAF peak were used as covariates. The control hypothesis would be confirmed by the following 2 statistical results: (1) a statistical ANOVA effect including the factor group $(p<0.05)$; and (2) a post hoc test indicating statistically significant differences of the occipital sources of alpha rhythms with the pattern Nold $>\mathrm{MCI}>\mathrm{AD}$ (Duncan test; $p<0.05$, one way).

The third statistical session tested the working hypothesis that amplitude of occipital sources of alpha rhythms is related to neurodegeneration in occipital lobe in the Nold, MCI, and AD subjects. To address this issue, we performed a correlation analysis by Pearson test between occipital normalized LORETA solutions (normalized current density at all voxels of occipital ROI) and occipital GMD in all Nold, MCI, and AD subjects as a whole group ( $p<$ 0.05).

\section{Results}

\subsection{Demographic, clinical, and neuropsychological data}

Table 2 summarizes relevant demographic (age, education, and gender) and clinical (MMSE) data of the enrolled Nold, MCI, and AD subjects. Three ANOVAs $(p<0.05)$ using the factor group (Nold, $\mathrm{MCI}, \mathrm{AD}$; independent variable) tested possible statistically

Table 2

Demographic (age, education, and gender) and clinical (Mini Mental State Examination, MMSE) indexes in healthy elderly individuals (Nold), amnesic mild cognitive impairment (MCI), and mild Alzheimer's disease (AD) subjects

\begin{tabular}{llll}
\hline & Nold & MCI & AD \\
\hline $\mathrm{N}$ & 45 & 100 & 90 \\
Age, $\mathrm{y}( \pm \mathrm{SE})$ & $70.1(1.1)$ & $70.7(0.8)$ & $72.3(0.8)$ \\
Education, $\mathrm{y}( \pm \mathrm{SE})$ & $9.4(0.7)$ & $8.8(0.4)$ & $8(0.5)$ \\
Gender $(\mathrm{F} / \mathrm{M})$ & $29 / 16$ & $59 / 41$ & $54 / 36$ \\
MMSE $( \pm$ SE) & $29.1(0.2)$ & $27.4(0.1)$ & $19(0.4)$ \\
\hline
\end{tabular}

Key: F, female; M, male; SE, standard error. significant differences of age, education, and MMSE score among the 3 groups, respectively. Furthermore, the Median test was used to evaluate possible statistically significant differences of gender among the 3 groups ( $p<0.05$; two ways). Only the ANOVA for the MMSE score showed a statistically significant difference among the groups $(F[2,232]=406.5, p<0.000001)$. Duncan post hoc testing indicated that the MMSE score was higher in the Nold group compared with the MCI $(p<0.00005)$ and the AD group $(p<$ $0.00005)$. Furthermore, the MMSE score was also higher in the $\mathrm{MCI}$ than in the $\mathrm{AD}$ group $(p<0.00005)$. No statistically significant difference was found for age $(\mathrm{F}[2,232]=1.6, p>0.05)$, education ( $\mathrm{F}$ $[2,232]=1.7, p>0.05)$, and gender $\left(\chi^{2}=0.8, p>0.05\right)$.

In some cases, different clinical centers used diverse neuropsychological tests to probe a given cognitive function. This prevented the computation and comparison of mean scores with neuropsychological tests in all $\mathrm{MCI}$ and $\mathrm{AD}$ patients of the present study. However, a general trend of patients' cognitive status is given by Table 3. It reports the mean ( \pm SE) scores of Trail Making Test part $A$ (TMT A), part B (TMT B), part B-A (TMT B-A), copy of Rey figures (Rey figures), delayed recall of Rey figures (Rey figures recall), verbal fluency for letters (letter fluency), and verbal fluency for fruits, animals or car trades (categorical fluency) in 2 large subgroups of $100 \mathrm{MCI}$ and $90 \mathrm{AD}$ subjects. Six $t$ tests for independent populations were computed to evaluate possible statistically significant differences of these mean scores in the 2 subgroups (MCI vs. AD; $p<0.05$, one way). A statistically significant difference was found for all 6 neuropsychological tests $(p<0.05)$ in that there was a lower performance in the $\mathrm{AD}$ compared with the $\mathrm{MCI}$ group.

\subsection{Topography of the EEG cortical sources as estimated by LORETA}

For illustrative purposes, Fig. 1 maps the grand average of the LORETA solutions (i.e., relative power current density at cortical voxels) modeling the distributed EEG cortical sources for delta, theta, alpha 1, alpha 2 , beta 1 , and beta 2 bands in the Nold, $\mathrm{MCI}$, and AD groups. The Nold group presented alpha 1 sources with the highest amplitude values in the occipital regions. Delta, theta, and alpha 2 sources had moderate amplitude values when compared with the alpha 1 sources. Finally, the beta 1 and beta 2 sources had lowest amplitude values. Compared with the Nold group, the AD group showed a dramatic reduction of the parietal and occipital alpha 1 sources and an increase of the delta source. With respect to the Nold and AD groups, the $\mathrm{MCI}$ group showed an intermediate magnitude of the occipital alpha 1 sources. In general, the cortical sources of these EEG rhythms across Nold, $\mathrm{MCI}$, and AD groups showed the most marked modulation in the occipital region.

Table 3

Mean scores ( \pm standard error, SE) of neuropsychological tests in 2 large subgroups of $100 \mathrm{MCI}$ and $90 \mathrm{AD}$ subjects

\begin{tabular}{lccl}
\hline & MCI & AD & $t$ test, $p$-value, df \\
\hline TMT A & $57.2(4.2)$ & $119.8(11.8)$ & $-5.2,<0.000001,188$ \\
TMT B & $171.7(13.1)$ & $340(25.8)$ & $-5.9,<0.000001,188$ \\
TMT B-A & $114.6(11)$ & $220.3(19.9)$ & $-4.6,<0.000005,188$ \\
Rey figures & $28.7(0.8)$ & $21.8(1.2)$ & $4.8,<0.000005,188$ \\
Rey figures recall & $12.6(0.8)$ & $8.1(0.6)$ & $4.4,<0.00001,188$ \\
Letter fluency & $29(1)$ & $24.7(1.2)$ & $2.73,<0.01,188$ \\
Category fluency & $34.5(1)$ & $28.1(1.1)$ & $4.2,<0.00005,188$ \\
\hline
\end{tabular}

Statistical comparison between the mean scores of the 2 subgroups was performed by $t$ tests for independent populations ( $p<0.05$, one way). The statistical results ( $t$ and $p$-value) are reported.

Categorical fluency indicates verbal fluency for fruits, animals, or car trades. Letter fluency indicates verbal fluency for letters. Rey figures indicate copy of Rey figures; Rey figures recall indicates delayed recall of Rey figures.

Key: AD, Alzheimer's disease; $\mathrm{MCI}$, mild cognitive impairment; TMT A, trail making test part A; TMT B, trail making test part B; TMT B-A, trail making test part $B$ to part A. 


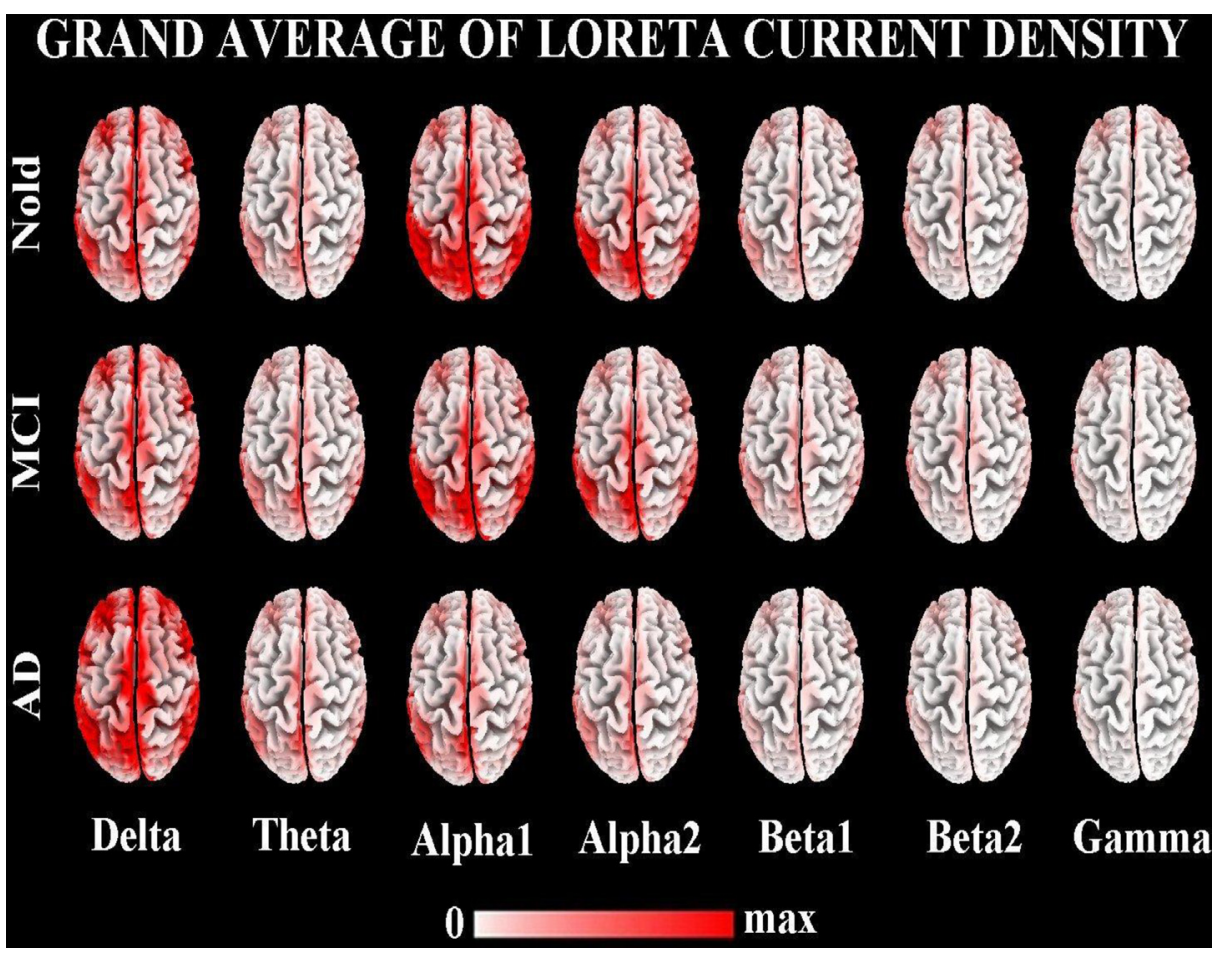

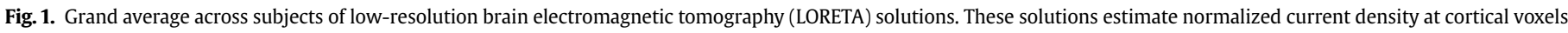

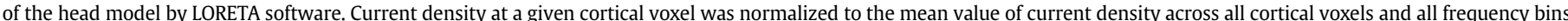

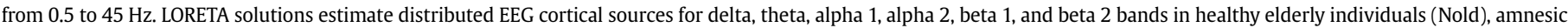

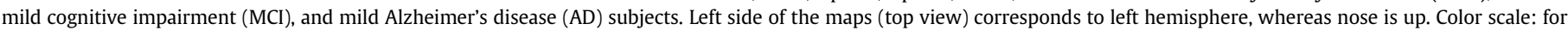

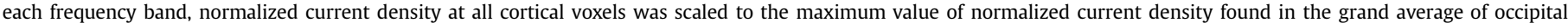

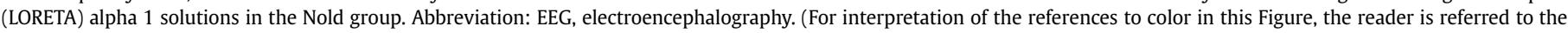
web version of this article.)

\subsection{Statistical comparisons}

Fig. 2 shows the mean value ( \pm SE) of occipital GMD for the Nold, $\mathrm{MCI}$, and AD groups. The mean occipital GMD was of 0.0229 $( \pm 0.0003 \mathrm{SE})$ for the Nold group, $0.0219( \pm 0.0002 \mathrm{SE})$ for the MCI group, and $0.0191( \pm 0.0002 \mathrm{SE})$ for the $\mathrm{AD}$ group. As expected, ANOVA for the evaluation of the first control hypothesis (i.e., difference of occipital GMD among the Nold, MCI, and AD groups) showed a statistically significant main effect for the factor group ( $F$ $[2,229]=41.9, p<0.00001)$. Duncan post hoc testing indicated that

\section{OCCIPITAL GREY MATTER DENSITY}

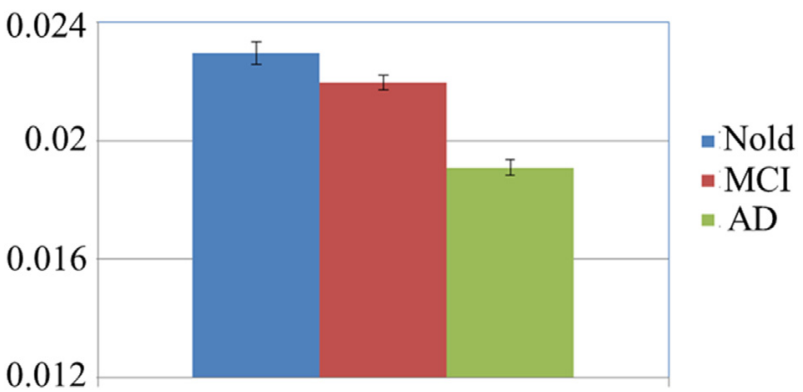

Fig. 2. Mean values ( \pm standard error, $S E$ ) of occipital gray matter density (GMD) as estimated from T1-weighted volumetric magnetic resonance images (MRIs) in Nold, $\mathrm{MCI}$, and $\mathrm{AD}$ groups. Extraction of the GMD marker was performed by functional magnetic resonance imaging of the brain (FMRIB) software library (FSL). GMD was defined as the probability of a brain voxel belonging to gray matter and resulted from the use of FSL-BET and FSL-FNIRT tools see section 2 for details. Abbreviations: AD, Alzheimer's disease; MCI, mild cognitive impairment. (For interpretation of the references to color in this Figure, the reader is referred to the web version of this article.) occipital GMD was higher in the Nold group compared with the $\mathrm{MCl}$ $(p<0.05)$ and the AD group $(p<0.00001)$. Occipital GMD was also higher in the MCI than in the AD group $(p<0.00001)$.

ANOVA for the evaluation of the second control hypothesis (i.e., difference of the occipital sources of alpha rhythms among the Nold, $\mathrm{MCI}$, and $\mathrm{AD}$ groups) showed a statistically significant interaction ( $\mathrm{F}$ $[60,6930]=13.27, p<0.0001)$ among the factors group $(\mathrm{AD}, \mathrm{MCI}$, and Nold), band (delta, theta, alpha 1 , alpha 2 , beta 1 , and beta 2 ), and ROI (central, frontal, parietal, occipital, temporal, and limbic). Fig. 3 shows the mean regional normalized LORETA solutions relative to this statistical interaction in the ANOVA. In the figure, the LORETA solutions in the cortical sources had the shape of EEG relative power spectra. Notably, the profile and magnitude of these spectra in the $\mathrm{AD}, \mathrm{MCI}$, and Nold groups differed across various cortical macroregions, supporting the idea that scalp EEG rhythms are generated by a distributed pattern of cortical sources. Duncan planned post hoc testing showed that cortical alpha 1 source pattern Nold $>\mathrm{MCI}>\mathrm{AD}$ was fitted by parietal, occipital, temporal, and limbic alpha 1 sources being amplitude of these sources greater in the Nold group compared with the $\mathrm{MCI}$ and the $\mathrm{AD}$ group (Nold $>\mathrm{AD}, p<0.000001$; Nold $>\mathrm{MCI}, p<0.00001)$ and in the MCI group compared with the AD group $(\mathrm{MCI}>\mathrm{AD}, p<0.000001)$.

Finally, Pearson test was used to evaluate the main working hypothesis; namely, the relationship between occipital sources of alpha rhythms and neurodegeneration in occipital lobe along the continuum of physiological and pathologic aging. A statistically significant positive correlation was found between amplitude of occipital sources of alpha 1 rhythms and occipital GMD in the Nold, $\mathrm{MCI}$, and $\mathrm{AD}$ subjects as a whole group $(\mathrm{r}=0.3, p<0.000005 ; \mathrm{N}=$ 235 ). The higher the amplitude of occipital sources of alpha 1 rhythms, the higher the occipital GMD (see Fig. 4). 


\section{STATISTICALANOVAINTERACTION AMONG GROUP, BAND, AND ROI}

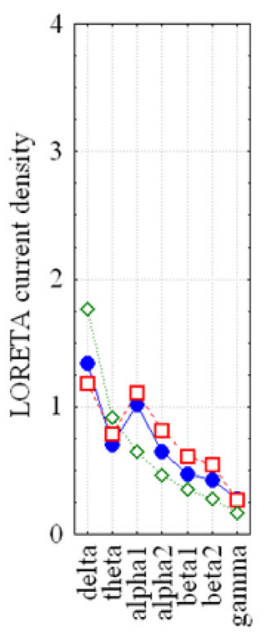

central

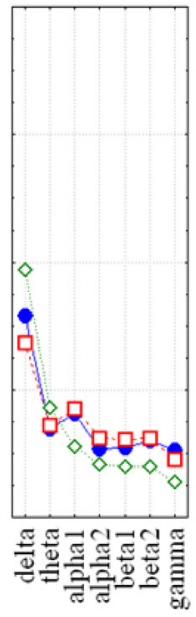

frontal

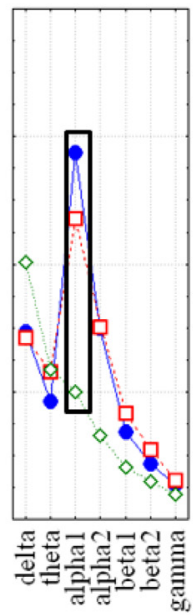

parietal

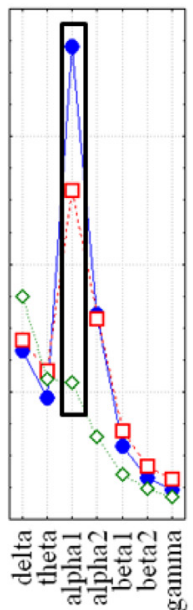

occipital

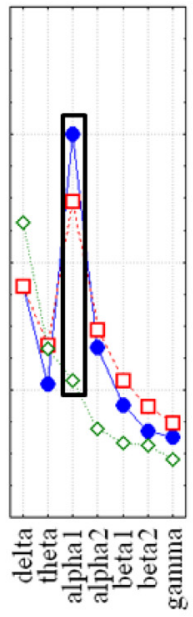

temporal

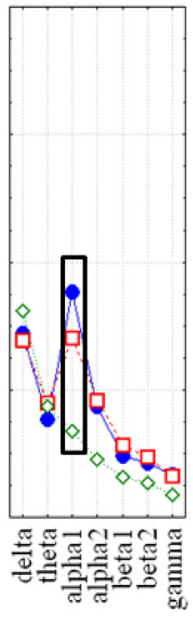

limbic

$\bullet$ Nold

… MCI

$=$ Nold $>\mathrm{MCI}>\mathrm{AD}$

$\because \mathrm{AD}$

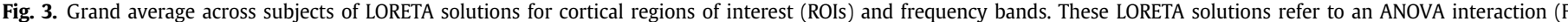

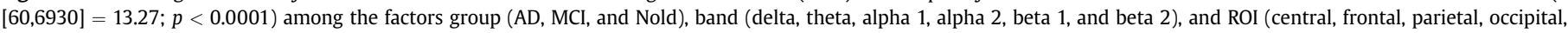

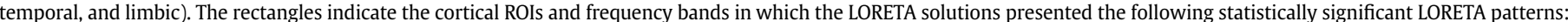

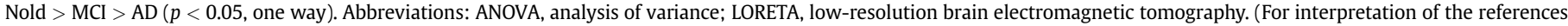
to color in this Figure, the reader is referred to the web version of this article.)

\subsection{Control analyses}

As previously mentioned, amplitude of occipital sources of alpha 1 rhythms positively correlated with occipital GMD in the Nold, $\mathrm{MCI}$, and AD subjects as a whole group ( $p<0.000005)$. To better understand this main finding, the following additional control analyses were performed. A first control analysis investigated whether a similar relationship was observed in the single groups (Nold, MCI, and AD) considered separately. To address this issue,

\section{SCATTERPLOT BETWEEN LORETA CURRENT DENSITY AND GREY MATTER DENSITY $\mathrm{I}=0.3, \mathrm{p}=0.000004$}

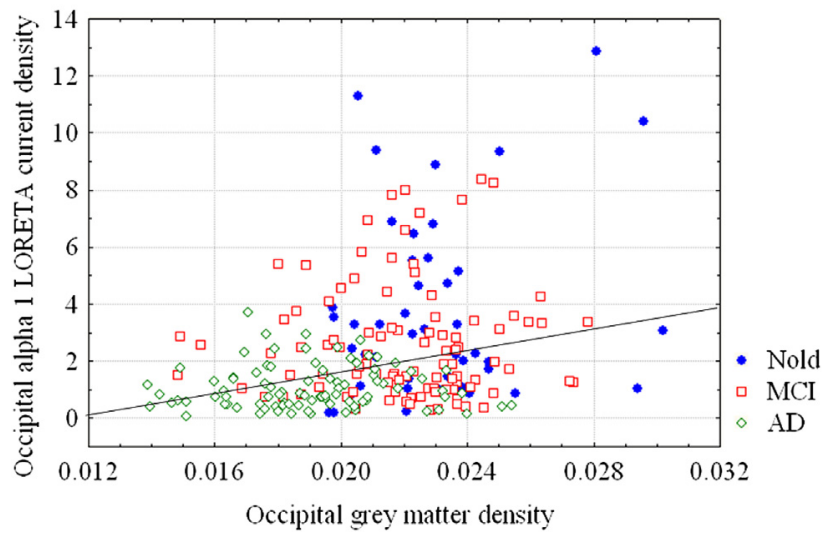

Fig. 4. Scatterplot of occipital LORETA sources of alpha 1 rhythms (i.e., normalized source current density at occipital ROI) and occipital GMD in all Nold, MCI, and AD subjects. Pearson test evaluated the hypothesis of a correlation between these 2 variables $(p<0.05)$. The $r$ and $p$-values are reported. Abbreviations: AD, Alzheimer's disease; GMD, gray matter density; LORETA, low-resolution brain electromagnetic tomography; $\mathrm{MCI}$, mild cognitive impairment; ROI, region of interest. (For interpretation of the references to color in this Figure, the reader is referred to the web version of this article.)
Pearson test was used to evaluate the hypothesis of a correlation between the amplitude of occipital sources of alpha 1 rhythms and the occipital GMD in the Nold, MCI, and AD subjects as a single groups $(p<0.05)$. Results showed no statistically significant correlations $(p=0.1)$.

A second control analysis investigated whether a similar relationship was observed between amplitude of temporal sources of alpha 1 rhythms and GMD in the temporal lobe, in line with previous evidence that temporal lobe atrophy is one of the most common MRI

\section{SCATTERPLOT BETWEEN LORETA CURRENT DENSITY AND GREY MATTER DENSITY $\mathrm{I}=0.29, \mathrm{p}=0.000005$}

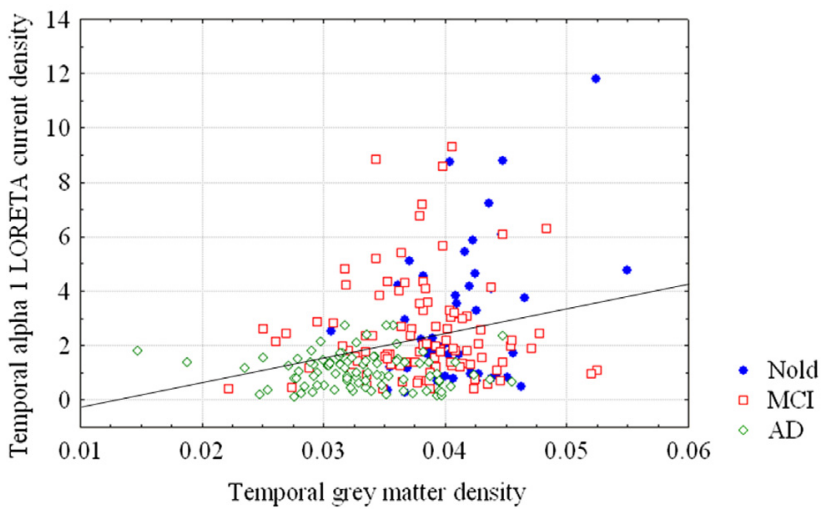

Fig. 5. Scatterplot of temporal LORETA sources of alpha 1 rhythms (i.e., normalized source current density at temporal ROI) and temporal GMD in all Nold, MCI, and AD subjects. Pearson test evaluated the hypothesis of a correlation between these 2 variables $(p<0.05)$. The $r$ and $p$-values are reported. Abbreviations: AD, Alzheimer's disease; GMD, gray matter density; LORETA, low-resolution brain electromagnetic tomography; $\mathrm{MCl}$, mild cognitive impairment; ROI, region of interest. (For interpretation of the references to color in this Figure, the reader is referred to the web version of this article.) 
findings in MCI and AD subjects (Baron et al., 2001; Frisoni et al., 2002; Ohnishi et al., 2001; Rombouts et al., 2000; Testa et al., 2004; Wolf et al., 2003). To address this issue, we estimated the GMD in all Nold, MCI, and AD subjects. The mean GMD in the temporal lobe was of $0.0412( \pm 0.0006 \mathrm{SE})$ for the Nold group, 0.038 $( \pm 0.0005 \mathrm{SE})$ for the MCI group, and $0.0331( \pm 0.0005 \mathrm{SE})$ for the AD group. Furthermore, an ANOVA $(p<0.05)$ evaluated whether temporal GMD differed among the Nold, MCI, and AD groups. The ANOVA factor was group (Nold, $\mathrm{MCI}$, and $\mathrm{AD}$; independent variable). Subjects' age, education, and gender were used as covariates. As expected based on the typical progress of neurodegenerative processes in the temporal lobe with aging, the ANOVA results showed a statistically significant main effect for the factor group $(F[2,229]=$ 41.6, $p<0.00001$ ). Duncan post hoc testing indicated that temporal GMD was higher in the Nold group compared with the MCI $(p<$ $0.0001)$ and the $\operatorname{AD~group~}(p<0.00001)$. It was also higher in the $\mathrm{MCI}$ compared with the AD group $(p<0.00001)$. Finally, Pearson test tested the hypothesis of a correlation between amplitude of temporal sources of alpha 1 rhythms and temporal GMD in the Nold, $\mathrm{MCI}$, and AD subjects as a whole group $(p<0.05)$. A statistically significant positive correlation was found $(\mathrm{r}=0.29, p<0.000005$; $\mathrm{N}=235)$. Indicating the higher the amplitude of temporal sources of alpha 1 rhythms, the higher the GMD in the temporal lobe (see Fig. 5).

A third control analysis tested the hypothesis that amplitude of occipital sources of alpha rhythms was related to cognitive status in the Nold, MCI, and AD subjects as a whole group. To address this issue, Pearson test was used evaluated the hypothesis of a correlation between amplitude of occipital sources of alpha 1 rhythms and MMSE score in the Nold, $\mathrm{MCI}$, and AD subjects as a whole group $(p<0.05)$. A statistically significant positive correlation was found $(\mathrm{r}=0.38, p<0.000001 ; \mathrm{N}=235)$. The higher the amplitude of occipital sources of alpha 1 rhythms, the better (higher) the MMSE score (see Fig. 6).

A fourth control analysis was performed to test the hypothesis that occipital GMD used for the correlation with occipital sources of alpha 1 rhythms was related to neurodegenerative processes in the temporal lobe as one of the most reliable indexes of AD. To address this issue, Pearson test evaluated the hypothesis of a correlation between occipital and temporal GMD in the Nold, MCI, and AD subjects as a whole group $(p<0.05)$. A statistically significant

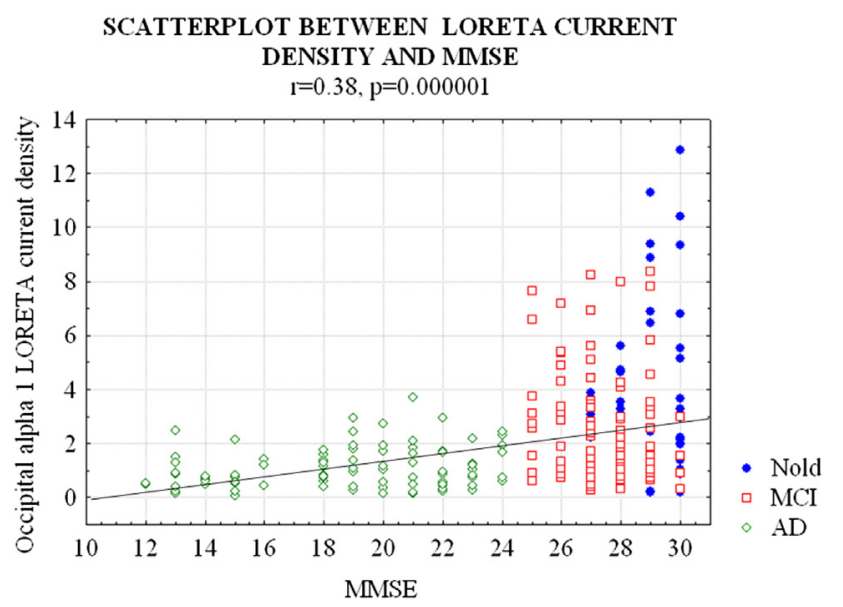

Fig. 6. Scatterplot of occipital LORETA sources of alpha 1 rhythms (i.e., normalized source current density at occipital ROI) and mini mental state examination (MMSE) score in all Nold, MCI, and AD subjects. Pearson test evaluated the hypothesis of a correlation between these 2 variables $(p<0.05)$. The $r$ and $p$-values are reported. Abbreviations: AD, Alzheimer's disease; LORETA, low-resolution brain electromagnetic tomography; $\mathrm{MCI}$, mild cognitive impairment; ROI, region of interest. (For interpretation of the references to color in this Figure, the reader is referred to the web version of this article.)

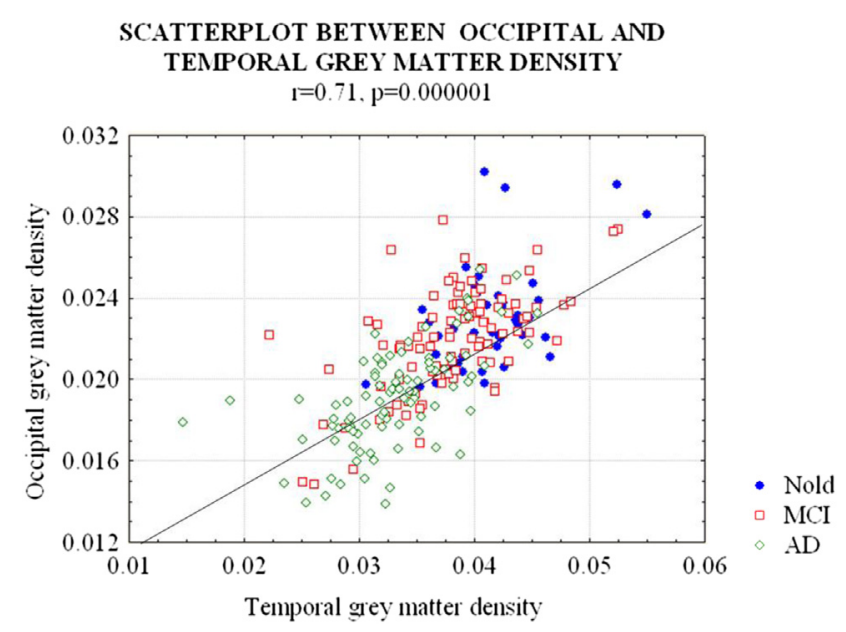

Fig. 7. Scatterplot of occipital and temporal GMD in all Nold, $\mathrm{MCI}$, and AD subjects. Pearson test evaluated the hypothesis of a correlation between these 2 variables ( $p<$ 0.05 ). The $r$ and $p$-values are reported. Abbreviations: AD, Alzheimer's disease; GMD, gray matter density; $\mathrm{MCl}$, mild cognitive impairment. (For interpretation of the references to color in this Figure, the reader is referred to the web version of this article.)

positive correlation was found $(\mathrm{r}=0.77, p<0.000001 ; \mathrm{N}=235)$. The higher the occipital GMD, the higher the temporal GMD (see Fig. 7).

A fifth control analysis tested the hypothesis that amplitude of occipital sources of alpha 1 rhythms allows a correct blind classification between individual Nold and AD subjects. To this aim, we used MedCalc software (Mariakerke, Belgium; http://www. medcalc.org/), which computes the receiver operating characteristic (ROC) curves (DeLong et al., 1988). Results showed that amplitude of occipital sources of alpha 1 rhythms allowed a moderate classification between Nold and AD subjects with sensitivity of $87.8 \%$, specificity of $66.7 \%$, and area under the ROC curve of 0.81 . The same analysis was repeated for frontal, central, parietal, temporal, and limbic alpha 1 sources. Results showed that sensitivity ranged from $90 \%$ to $54.4 \%$, specificity ranged from $73.3 \%$ to $62.6 \%$, and area under the ROC curve ranged from 0.78 to 0.65 (see Fig. 8).

\section{ROC curve}

Alpha 1 LORETA current density

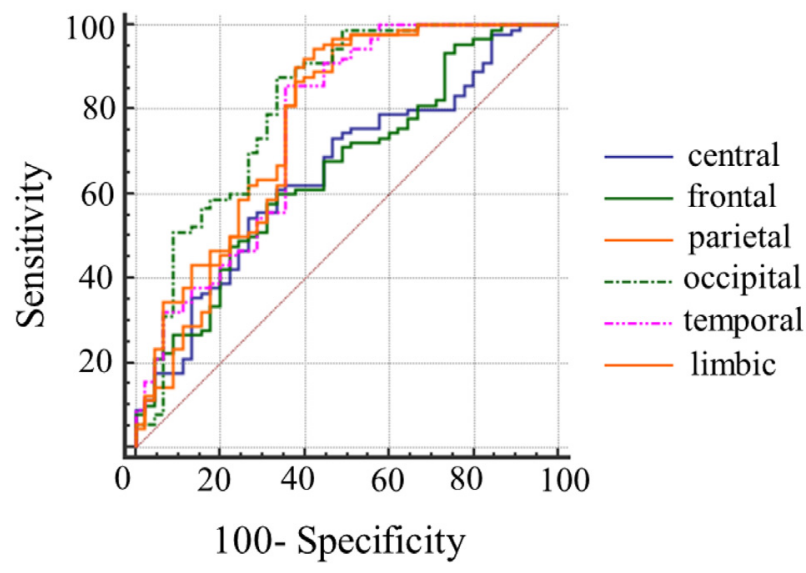

Fig. 8. Mean receiver operating characteristic (ROC) curve illustrating the results of the classification of individual Nold and AD subjects based on amplitude of (LORETA) cortical sources of alpha 1 rhythms (i.e., normalized source current density at central, frontal, parietal, occipital, temporal, and limbic ROIs of brain model used by LORETA software). Abbreviations: AD, Alzheimer's disease; LORETA, low-resolution brain electromagnetic tomography. (For interpretation of the references to color in this Figure, the reader is referred to the web version of this article.) 


\section{ROC curve}

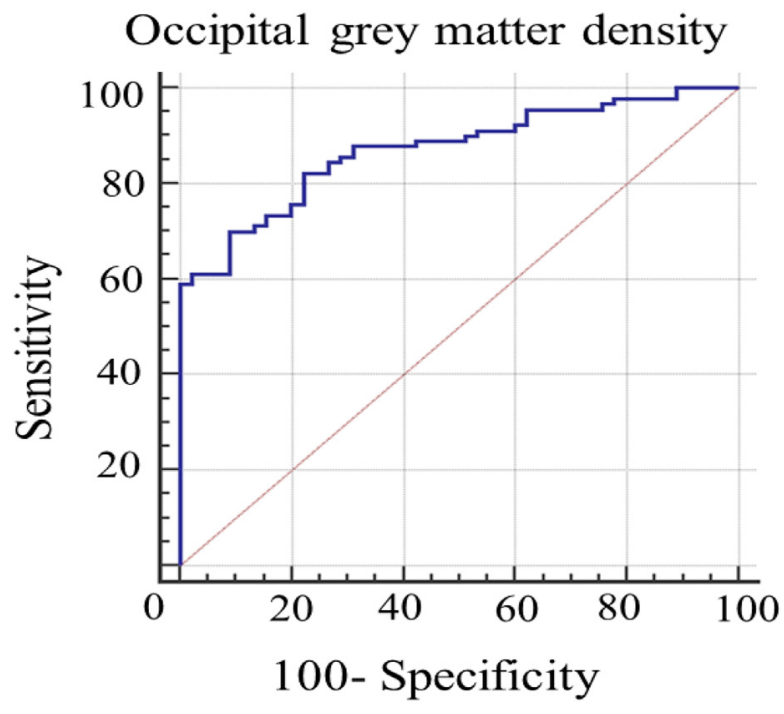

Fig. 9. Mean receiver operating characteristic (ROC) curve illustrating the results of the classification of individual Nold and AD subjects based on occipital GMD. Abbreviations: $\mathrm{AD}$, Alzheimer's disease; GMD, gray matter density. (For interpretation of the references to color in this Figure, the reader is referred to the web version of this article.)

Of note, no alpha source allowed a remarkable classification between the $\mathrm{AD}$ and $\mathrm{MCI}$ subjects, possibly because of the relatively small amount of subjects and/or a certain amount of prodromic AD patients in the present MCI subjects.

A sixth control analysis tested the hypothesis that occipital GMD allows a correct blind classification between individual Nold and AD subjects. Results showed a moderate to high classification of the Nold and AD subjects' sensitivity of $70.0 \%$, specificity of $91.1 \%$, and area under the ROC curve of 0.87 (see Fig. 9), thus confirming that occipital GMD is a valid MRI marker of AD neurodegeneration along pathologic aging.

A seventh control analysis was used to cross-validate the results of correlation between amplitude of occipital sources of alpha rhythms and occipital GMD in all Nold, MCI, and AD subjects as a whole group. To this aim, Pearson test was used to test the hypothesis that alpha 1 power density at occipital scalp electrodes (i.e., $\mathrm{O} 1$ and 02 ) correlated with occipital GMD across all Nold, $\mathrm{MCI}$, and $\mathrm{AD}$ subjects as a whole group $(p<0.05)$. Power density values of $\mathrm{O} 1$ and $\mathrm{O} 2$ electrodes were averaged. A statistically significant positive correlation was found $(\mathrm{r}=0.3, p<0.000005 ; \mathrm{N}=235)$. The higher the occipital scalp alpha 1 power density, the higher the occipital GMD (see Fig. 10), in line with main results based on amplitude of occipital sources of alpha rhythms. It should be noted that an advantage of using cortical source estimation of EEG rhythms is that effects of head volume conductor are taken into account. Although the EEG activity recorded at occipital scalp electrodes can depend not only on occipital but also on parietal and temporal sources.

\section{Discussion}

Here, we tested the hypothesis that across the continuum of physiological and pathologic aging, amplitude of the occipital sources of resting-state alpha rhythms is related to neurodegeneration in the occipital lobe as quantified by the GMD estimated from structural MRIs in Nold, MCI, and AD subjects. In this regard, one might claim that GMD in the occipital lobe represents a

\section{SCATTERPLOT BETWEEN SCALP POWER DENSITY AND GREY MATTER DENSITY $\mathrm{r}=0.3, \mathrm{p}=0.000005$}

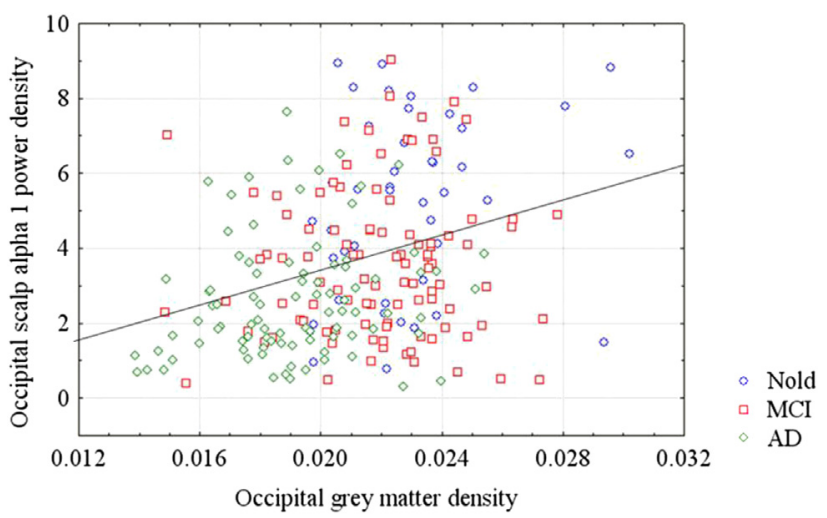

Fig. 10. Scatterplot of occipital scalp alpha 1 power density and occipital GMD in all Nold, $\mathrm{MCI}$, and AD subjects. Pearson test evaluated the hypothesis of a correlation between these 2 variables $(p<0.05)$. The $\mathrm{r}$ and $p$-values are reported. Abbreviations: $\mathrm{AD}$, Alzheimer's disease; GMD, gray matter density; $\mathrm{MCI}$, mild cognitive impairment. (For interpretation of the references to color in this Figure, the reader is referred to the web version of this article.)

partial index of the neurodegeneration in the AD process. Indeed, $\mathrm{AD}$ is thought to be a multifocal process that evolves over time and selectively impacts specific subcortical and cortical neuronal regions rather than preferentially affecting occipital neocortex (Braak and Braak, 1996). However, the interest here in the occipital lobe is motivated by the fact that occipital alpha rhythms are the dominant oscillatory activity in humans during the condition of eyes-closed resting state, and these signals are markedly abnormal in $\mathrm{MCI}$ and AD subjects (Babiloni et al., 2006a, 2007). These spontaneous cortical rhythms are a promising marker for a preliminary large screening of elderly subjects at risk of prodromal AD - these could include subjects with genetic risk factors for developing AD or with subjective or objective memory deficits. However, such an EEG marker needs to be further validated by the correlation with overt signs of neurodegeneration across the continuum between physiological and pathologic aging represented by Nold, $\mathrm{MCI}$, and $\mathrm{AD}$ subjects.

In the present study, we estimated occipital GMD instead of the gray matter volume, in line with the idea that the alterations in GMD may optimally account for cortical neuronal loss provoked by AD neurodegeneration (Kassubek et al., 2004; Mummery et al., 2000). However, we cannot rule out the possibility that some GMD changes could occur for reasons other than the neuronal loss (i.e., changes in signal properties or widening of CSF spaces; Kassubek et al., 2002). As expected, results showed that occipital GMD was higher in the Nold group compared with the $\mathrm{MCI}$ and the AD group. Occipital GMD was also higher in the $\mathrm{MCI}$ compared with the $\mathrm{AD}$ group. In general, the present results extend previous evidence showing that at different times over the course of $A D$, the reduction of the GMD as measured from MRIs reflects severity of the disease in the spectrum ranging from $\mathrm{MCI}$ to $\mathrm{AD}$ condition (Frisoni et al., 2009).

We also found that the amplitude of the occipital sources of lowfrequency alpha rhythms $(8-10.5 \mathrm{~Hz})$ was greatest in the Nold, intermediate in the $\mathrm{MCI}$, and lowest in the AD subjects. Furthermore, there was a positive correlation between amplitude of these occipital alpha sources and global cognitive status as revealed by MMSE score in the Nold, MCI, and AD subjects considered as a whole group. Finally, occipital sources of low-frequency alpha rhythms allowed a moderate classification between Nold and AD subjects with $87.8 \%$ of sensitivity, $66.7 \%$ of specificity, and area 
under the ROC curve of 0.81 . These results are generally in line with prior evidence that resting-state alpha rhythms do decrease in amplitude in $\mathrm{AD}$ and $\mathrm{MCI}$ compared with Nold subjects (Babiloni et al., 2006a, 2007; Dierks et al., 1993, 2000; Koenig et al., 2005; Moretti et al., 2004; Rodriguez et al., 1999a, 1999b; for a reviewRossini et al., 2007). Furthermore, they confirm the bulk of previous evidence showing a positive correlation between the amplitude of the (LORETA) occipital sources of low-frequency alpha rhythms and the MMSE score in $\mathrm{MCI}$ and AD subjects (Babiloni et al., 2006a, 2007). Finally, the present findings are in line with those showing that spectral EEG markers classified Nold from early stages of AD with $89 \%-95 \%$ success (Adler et al., 2003; Bennys et al., 2001; Buscema et al., 2007; Claus et al., 1999; Huang et al., 2000; Lehmann et al., 2007; Leuchter et al., 1987; Missonnier et al., 2006; Nuwer, 1997). On the whole, the present results validated the subjects selection and the EEG data analysis with the LORETA software. Furthermore, they confirmed that the occipital sources of low-frequency alpha rhythms are related to individual cognitive status in amnesic $\mathrm{MCI}$ and $\mathrm{AD}$ patients.

As a novel finding of the present study, here, we found a positive correlation between the GMD in the occipital lobe and the amplitude of the occipital sources of low-frequency alpha rhythms in the $\mathrm{MCI}$ and AD subjects as a whole group. The lower the GMD in the occipital lobe, the lower the amplitude of these occipital sources. Notably, this linear correlation was statistically significant $(p<$ $0.000005)$ but relatively low in magnitude $(r=0.3)$, possibly because of a complex relationship occurring between the neurodegeneration in the occipital lobe and synchronous activity of cortical pyramidal neurons generating occipital alpha rhythms in humans during eyes-closed resting state. Of note, the single groups considered separately (e.g., Nold, $\mathrm{MCI}$, and AD) did not show statistically significant correlation values between the occipital GMD and the amplitude of the occipital sources of low-frequency alpha rhythms $(p>0.05)$, possibly because of the relatively small range of the occipital alpha 1 and/or of the occipital GMD values within these single groups. The relationship between GMD in the occipital lobe and occipital sources of low-frequency alpha rhythms may be better captured by nonlinear predictors such as artificial neural networks (Buscema et al., 2007). Future studies should address this interesting direction.

The present results extend previous evidence that EEG rhythms in $\mathrm{MCI}$ and $\mathrm{AD}$ subjects are related to the loss of neurons as revealed by the atrophy of brain gray or white matter (Fernandez et al., 2003). The bilateral reduction of hippocampal and entorhinal volumes in $\mathrm{AD}$ subjects is known to be correlated with an increase in cortical delta rhythms (Fernandez et al., 2003). Furthermore, the frontal white matter atrophy was related to the amplitude of frontal delta sources $(2-4 \mathrm{~Hz}$ ) in $\mathrm{MCI}$ and $\mathrm{AD}$ subjects (Babiloni et al., 2006b). In these subjects, the atrophy of hippocampus was related to the decline of alpha sources (Babiloni et al., 2009a), whereas global cortical gray matter volume was negatively correlated with the amplitude of widespread delta sources and positively correlated with the amplitude of widespread alpha 1 sources (Babiloni et al., 2013).

Our results highlight interesting aspects of the generation of resting-state alpha rhythms in humans as a basis for the use of "occipital alpha" markers for clinical applications and pharmacologic trials on $\mathrm{AD}$. An overview of these aspects is reported in the following. There is consensus that main generators of resting-state alpha rhythms in humans are visual, somatomotor, and auditory cortical areas and that occipital alpha rhythms $(8-13 \mathrm{~Hz})$ are the dominant oscillatory activity in the eyes-closed resting-state condition (Rossini et al., 1991; Klimesch, 1996; Klimesch et al., 1997, 1998; Pfurtscheller and Lopes da Silva, 1999). The occipital alpha rhythms may reflect cycles of excitation and inhibition of the visual cortex. These cycles might gate the flow of visual information during the eyes-closed condition (Pfurtscheller and Lopes da Silva, 1999), whereas they might frame perceptual events in discrete snapshots of around $70-100 \mathrm{~ms}$ during active visual information processing (Fingelkurts and Fingelkurts, 2006; Mathewson et al., 2009). In general, intrinsic features of alpha rhythms affect our ability to accurately select, consciously perceive, and memorize visual stimuli (Babiloni et al., 2007; Klimesch, 1999; Mathewson et al., 2009, 2011; Varela et al., 1981). In this theoretical framework, the low-frequency $(8-10.5 \mathrm{~Hz})$ alpha rhythms would reflect the global cortical arousal and attention (Klimesch, 1996; Klimesch et al., 1997, 1998; Rossini et al., 1991; Steriade and Llinas, 1988). The higher the amplitude of occipital alpha rhythms, the lower the local cortical arousal as demonstrated by the co-registration of resting-state EEG rhythms and functional MRI (Gonçalves et al., 2006; Laufs et al., 2003; Mantini et al., 2007). Previous EEG-fMRI evidence also emphasized the important role of the thalamus in the generation of occipital alpha rhythms; namely, the higher the occipital alpha power, the higher the thalamic activation (Gonçalves et al., 2006). In the same vein, single unit recordings in animal models have shown that occipital alpha rhythms are mainly generated by the oscillatory activity of occipital pyramidal neurons in response to important inputs delivered by both high-threshold bursting and relay-mode thalamocortical neurons of the lateral geniculate nucleus (Lorincz et al., 2009), when excited by glutamatergic and cholinergic inputs (Hughes and Crunelli, 2005). These neurons entrain thalamic GABAergic interneurons of the lateral geniculate nucleus that, when potentiated by cholinergic inputs, finely suppress relay-mode thalamocortical neurons at the pace of negative or positive peaks of thalamic alpha rhythms (Lorincz et al., 2009). This leads to an effective fine temporal framing of the output of the relay-mode thalamocortical neurons (Lorincz et al., 2009). Relay-mode thalamocortical neurons also receive feedback excitatory glutamatergic inputs from cortical pyramidal neurons (Suffczynski et al., 2001) and cholinergic inputs from neurons of nucleus basalis of Meynert (Lorincz et al., 2008; Mesulam, 1995; Pinault and Deschenes, 1992). These neurons of the nucleus basalis of Meynert target the occipital cortical neurons and visual processes as well (Nobili and Sannita, 1997). Along the AD progression, these cholinergic innervations would be targeted by neurodegenerative processes (Helkala et al., 1996; Holschneider et al., 1999; Mesulam et al., 2004; Ricceri et al., 2004; Teipel et al., 2005), especially in patients not responding to long-term cholinergic therapy (Tanaka et al., 2003). As a functional counterpart, temporal, parietal, and occipital sources of the resting alpha rhythms were especially impaired in $\mathrm{AD}$ patients not responding to cholinergic therapy (Babiloni et al., 2006c). Finally, the occipital sources of alpha rhythms in amnesic $\mathrm{MCI}$ subjects deranged in association with the impairment of the cholinergic connections to cerebral cortex (Babiloni et al., 2009b).

Keeping in mind the previously mentioned overview, it can be speculated that the resting-state occipital alpha rhythms reflect both the impairment of cholinergic neuromodulation from basal forebrain to thalamus and/or occipital cortex and the relative neurodegeneration processes at occipital cortical gray matter (Helkala et al., 1996; Holschneider et al., 1999; Mesulam et al., 2004). This impairment would disinhibit cortical slow oscillators triggering resting delta rhythms (Steriade, 2003), which are a typical finding in occipital lobe of $\mathrm{AD}$ patients (Babiloni et al., 2006a, 2007). Furthermore, global effect of the cholinergic modulation of the alpha rhythms might depend on the complex interaction with the glutamatergic and GABAergic neuromodulatory systems unveiled in the recent animal studies on alpha rhythms in the populations of thalamic neurons (Hughes and Crunelli, 2005; Lorincz et al., 2008, 2009). MCI and AD patients might present alterations in excitatory-inhibitory balance of thalamic and cortical 
neurons as a primary mechanism contributing to cognitive decline. As a matter of fact, $\mathrm{AD}$ is characterized by alterations of particular $\operatorname{GABA}(A)$ receptor subunits, a net decrease of inhibitory neurotransmission, and increased incidence of seizure activity (Limon et al., 2011). Furthermore, there is a depression of cholinergic inhibitory activity and an enhancement of excitatory glutamatergic non-NMDA receptor activity as revealed by transcranial magnetic stimulation (Di Lazzaro et al., 2004; Ferreri et al., 2003). These pathologic effects might result in a tonic desynchronization of occipital alpha rhythms.

The previously mentioned speculation should be considered as tentative at this early stage of research. Even dopaminergic and serotoninergic systems could play a role in the fluctuation of resting-state occipital alpha rhythms in $\mathrm{AD}$ patients. Monoaminergic disturbances are characteristic not only of depression but also of AD (Korczyn and Halperin, 2009). Finally, concomitant use of selective serotonin-enhancing agents and AChEIs provides greater benefit in activities of daily living and global functioning in mild-tomoderate AD patients (Mowla et al., 2007).

In conclusion, the present study evaluated the hypothesis that the activity of the occipital sources of resting-state alpha rhythms are related to the neurodegeneration of the occipital lobe as indexed by GMD computed from MRIs across the continuum between physiological and pathologic aging represented by Nold, $\mathrm{MCI}$, and AD subjects. Results showed a positive correlation between the GMD and amplitude of occipital sources of low-frequency alpha rhythms in all Nold, $\mathrm{MCI}$, and $\mathrm{AD}$ subjects as a whole group. Furthermore, there was a positive correlation between amplitude of occipital sources of low-frequency alpha rhythms and cognitive status as revealed by MMSE score in these subjects. Finally, amplitude of occipital sources of low-frequency alpha rhythms allowed a moderate classification of individual Nold and AD subjects with sensitivity of $87.8 \%$, specificity of $66.7 \%$, and area under the ROC curve of 0.81 . These results suggest that occipital sources of resting-state low-frequency alpha rhythms are related to $\mathrm{AD}$ neurodegeneration in the occipital lobe. Future studies should test the hypothesis that this EEG marker may be clinically useful as noninvasive, largely available, and cost-effective neurophysiologic biomarker for the following non mutually exclusive applications: (1) preliminary screening and monitoring of elderly subjects at high risk to develop AD dementia such as people with ApoE4 or Cystatin $C$ genotyping or mutations of familial AD; (2) monitoring along time of elderly subjects at high risk to develop AD based on positivity to amyloid beta in cerebrospinal fluid, amyloidosis in the brain as revealed by ligand PET, posterior brain hypometabolism as revealed by fluorodeoxyglucose positron emission tomography and/or hippocampus atrophy as revealed by structural MRI; (3) enrichment of an early diagnosis of AD in those people; and (4) evaluation of the effect of therapy against AD in patients with a prodromic or manifest form of the disease.

\section{Acknowledgements}

The present study was developed and granted in the framework of the following projects: "Does rehabilitation with a $10-\mathrm{Hz}$ sensory stimulation improve brain rhythms and cognitive-motor performance in neurological patients? Towards Internet-based clinical applications at subjects", (Italian Ministry of Health, GR2008-1143090), “Smart Health 2.0" (Italian Ministry of University and Technological Research, Pon04a2_C-MIUR D.D. 626/Ric e 703/ Ric), “CONNAGE” (Italian Ministry of University and Technological Research, PRIN2010-2011, prot. 2010SH7H3F), and "Diagnostic Enhancement of Confidence by an International Distributed Environment" (DECIDE; FP7 ICT "infrastructure" 2010-2012; www.eudecide.eu/). The authors thank Dr Giulia Santi for his precious contribution for the evaluation of cortical atrophy from magnetic resonance imaging (MRI) using Functional Magnetic Resonance Imaging of the Brain Software Library. They thank Dr Fabrizio Vecchio for his precious contribution in an early stage of this study carried out in 47 subjects using another methodology for the evaluation of cortical atrophy from MRI. The results of that early study were really useful for the planning and execution of the present study in 235 subjects with a methodology better applicable to large databases of MRIs.

\section{References}

Adler, G., Brassen, S., Jajcevic, A., 2003. EEG coherence in Alzheimer's dementia. J. Neural Transm. 110, 1051-1058.

Albert, M.S., DeKosky, S.T., Dickson, D., Dubois, B., Feldman, H.H., Fox, N.C., Gamst, A. Holtzman, D.M., Jagust, W.J., Petersen, R.C., Snyder, P.J., Carrillo, M.C., Thies, B., Phelps, C.H., 2011. The diagnosis of mild cognitive impairment due to Alzheimer's disease: recommendations from the National Institute on Aging-Alzheimer's Association workgroups on diagnostic guidelines for Alzheimer's disease. Alzheimers Dement. 7, 270-279. Epub 2011 Apr 21.

Albert, M., Smith, L.A., Scherr, P.A., Taylor, J.O., Evans, D.A., Funkenstein, H.H., 1991. Use of brief cognitive tests to identify individuals in the community with clinically diagnosed Alzheimer's disease. Int. J. Neurosci. 57, 167-178.

Arnaiz, E., Almkvist, O., 2003. Neuropsychological features of mild cognitive impairment and preclinical Alzheimer's disease. Acta Neurol. Scand. Suppl. 179, $34-41$.

Babiloni, C., Binetti, G., Cassetta, E., Dal Forno, G., Del Percio, C., Ferreri, F., Ferri, R. Frisoni, G., Hirata, K., Lanuzza, B., Miniussi, C., Moretti, D.V., Nobili, F., Rodriguez, G., Romani, G.L., Salinari, S., Rossini, P.M., 2006a. Sources of cortical rhythms change as a function of cognitive impairment in pathological aging: a multi-centric study. Clin. Neurophysiol. 117, 252-268.

Babiloni, C., Carducci, F., Lizio, R., Vecchio, F., Baglieri, A., Bernardini, S., Cavedo, E. Bozzao, A., Buttinelli, C., Esposito, F., Giubilei, F., Guizzaro, A., Marino, S., Montella, P., Quattrocchi, C.C., Redolfi, A., Soricelli, A., Tedeschi, G., Ferri, R., Rossi-Fedele, G., Ursini, F., Scrascia, F., Vernieri, F., Pedersen, T.J., Hardemark, H.G., Rossini, P.M., Frisoni, G.B., 2013. Resting state cortical electroencephalographic rhythms are related to gray matter volume in subjects with mild cognitive impairment and Alzheimer's disease. Hum Brain Mapp. 34, 1427-1446.

Babiloni, C., Cassetta, E., Binetti, G., Tombini, M., Del Percio, C., Ferreri, F., Ferri, R. Frisoni, G., Lanuzza, B., Nobili, F., Parisi, L., Rodriguez, G., Frigerio, L., Gurzì, M., Prestia, A., Vernieri, F., Eusebi, F., Rossini, P.M., 2007. Resting EEG sources correlate with attentional span in mild cognitive impairment and Alzheimer's disease. Eur. J. Neurosci. 25, 3742-3757.

Babiloni, C., Cassetta, E., Dal Forno, G., Del Percio, C., Ferreri, F., Ferri, R., Lanuzza, B., Miniussi, C., Moretti, D.V., Nobili, F., Pascual-Marqui, R.D., Rodriguez, G., Luca Romani, G., Salinari, S., Zanetti, O., Rossini, P.M., 2006c. Donepezil effects on sources of cortical rhythms in mild Alzheimer's disease: responders vs. nonresponders. Neuroimage 31, 1650-1665. Epub 2006 Apr 5.

Babiloni, C., Frisoni, G.B., Pievani, M., Vecchio, F., Lizio, R., Buttiglione, M., Geroldi, C., Fracassi, C., Eusebi, F., Ferri, R., Rossini, P.M., 2009a. Hippocampal volume and cortical sources of EEG alpha rhythms in mild cognitive impairment and Alzheimer disease. Neuroimage 1, 123-135.

Babiloni, C., Frisoni, G., Steriade, M., Bresciani, L., Binetti, G., Del Percio, C. Geroldi, C., Miniussi, C., Nobili, F., Rodriguez, G., Zappasodi, F., Carfagna, T. Rossini, P.M., 2006b. Frontal white matter volume and delta EEG sources negatively correlate in awake subjects with mild cognitive impairment and Alzheimer's disease. Clin. Neurophysiol. 117, 1113-1129.

Babiloni, C., Pievani, M., Vecchio, F., Geroldi, C., Eusebi, F., Fracassi, C., Fletcher, E., De Carli, C., Boccardi, M., Rossini, P.M., Frisoni, G.B., 2009b. White-matter lesions along the cholinergic tracts are related to cortical sources of EEG rhythms in amnesic mild cognitive impairment. Hum. Brain Mapp. 30, 1431-1443.

Bachman, D.L., Wolf, P.A., Linn, R.T., Knoefel, J.E., Cobb, J.L., Belanger, A.J., White, L.R., D’Agostino, R.B., 1993. Incidence of dementia and probable Alzheimer's disease in a general population: the Framingham Study. Neurology 43 (3 Pt 1), 515-519.

Baron, J.C., Chételat, G., Desgranges, B., Perchey, G., Landeau, B., de la Sayette, V., Eustache, F., 2001. In vivo mapping of gray matter loss with voxel-based morphometry in mild Alzheimer's disease. Neuroimage 14, 298-309.

Bennett, D.A., Wilson, R.S., Schneider, J.A., Evans, D.A., Beckett, L.A., Aggarwal, N.T., Barnes, L.L., Fox, J.H., Bach, J., 2002. Natural history of mild cognitive impairment in older persons. Neurology 59, 198-205.

Bennys, K., Rondouin, G., Vergnes, C., Touchon, J., 2001. Diagnostic value of quantitative EEG in Alzheimer disease. Neurophysiol. Clin. 31, 153-160.

Braak, H., Braak, E., 1991. Neuropathological stageing of Alzheimer-related changes. Acta Neuropathol. 82, 239-259.

Braak, H., Braak, E., 1996. Evolution of the neuropathology of Alzheimer's disease. Acta Neurol. Scand. Suppl. 165, 3-12. Review.

Buscema, M., Rossini, P., Babiloni, C., Grossi, E., 2007. The IFAST model, a novel parallel nonlinear EEG analysis technique, distinguishes mild cognitive impairment and Alzheimer's disease patients with high degree of accuracy. Artif. Intell. Med. 40, 127-141. 
Carlesimo, G.A., Caltagirone, C., Gainotti, G., 1996. The group for the standardization of the mental deterioration battery. The mental deterioration battery: normative data, diagnostic reliability and qualitative analyses of cognitive impairment. Eur. Neurol. 36, 378-384.

Caso, F., Cursi, M., Magnani, G., Fanelli, G., Falautano, M., Comi, G., Leocani, L., Minicucci, F., 2012. Quantitative EEG and LORETA: valuable tools in discerning FTD from AD. Neurobiol. Aging 33, 2343-2356.

Chandler, M.J., Lacritz, L.H., Cicerello, A.R., Chapman, S.B., Honig, L.S., Weiner, M.F., Cullum, C.M., 2004. Three-word recall in normal aging. J. Clin. Exp. Neuropsychol. 26, 1128-1133.

Claus, J.J., Strijers, R.L., Jonkman, E.J., Ongerboer de Visser, B.W., Jonker, C., Walstra, G.J., Scheltens, P., van Gool, W.A., 1999. The diagnostic value of electroencephalography in mild senile Alzheimer's disease. Clin. Neurophysiol. 110, 825-832.

Devanand, D.P., Folz, M., Gorlyn, M., Moeller, J.R., Stem, J., 1997. Questionable dementia: clinical course and predictors of outcome. J. Am. Geriatr. Soc. 45, $321-328$.

Dierks, T., Ihl, R., Frolich, L., Maurer, K., 1993. Dementia of the Alzheimer type: effects on the spontaneous EEG described by dipole sources. Psychiatry Res. 50, $151-162$.

Dierks, T., Jelic, V., Pascual-Marqui, R.D., Wahlund, L.O., Julin, P., Linden, D.E.J., Maurer, K., Winblad, B., Nordberg, A., 2000. Spatial pattern of cerebral glucose metabolism (PET) correlates with localization of intracerebral EEG-generators in Alzheimer's disease. Clin. Neurophysiol. 111, 1817-1824.

Di Lazzaro, V., Oliviero, A., Pilato, F., Saturno, E., Dileone, M., Marra, C., Daniele, A., Ghirlanda, S., Gainotti, G., 2004. Tonali PA motor cortex hyperexcitability to transcranial magnetic stimulation in Alzheimer's disease. J. Neurol. Neurosurg. Psychiatry 75, 555-559.

DeLong, E.R., DeLong, D.M., Clarke-Pearson, D.L., 1988. Comparing the areas under two or more correlated receiver operating characteristic curves: a nonparametric approach. Biometrics 44, 837-845.

De Renzi, E., Vignolo, L.A., 1962. The token test: a sensitive test to detect receptive disturbances in aphasics. Brain 85, 665-678.

Dubois, B., Feldman, H.H., Jacova, C., Dekosky, S.T., Barberger-Gateau, P., Cummings, J., Delacourte, A., Galasko, D., Gauthier, S., Jicha, G., Meguro, K., O’brien, J., Pasquier, F., Robert, P., Rossor, M., Salloway, S., Stern, Y., Visser, P.J., Scheltens, P., 2007. Research criteria for the diagnosis of Alzheimer's disease: revising the NINCDS-ADRDA criteria. Lancet Neurol. 6, 734-746. Review.

Elmstahl, S., Rosen, I., 1997. Postural hypotension and EEG variables predict cognitive decline: results from a 5-year follow-up of healthy elderly women. Dement Geriatr. Cogn. Disord. 8, 180-187.

Fernandez, A., Arrazola, J., Maestu, F., Amo, C., Gil-Gregorio, P., Wienbruch, C., Ortiz, T., 2003. Correlations of hippocampal atrophy and focal low-frequency magnetic activity in Alzheimer disease: volumetric MR imagingmagnetoencephalographic study. AJNR Am. J. Neuroradiol. 24, 481-487.

Ferreri, F., Pauri, F., Pasqualetti, P., Fini, R., Dal Forno, G., Rossini, P.M., 2003. Motor cortex excitability in Alzheimer's disease: a transcranial magnetic stimulation study. Ann. Neurol. 53, 102-108.

Fingelkurts, A.A., Fingelkurts, A.A., Kivisaari, R., Autti, T., Borisov, S., Puuskari, V., Jokela, O., Kähkönen, S., 2006. Increased local and decreased remote functional connectivity at EEG alpha and beta frequency bands in opioid-dependent patients. Psychopharmacology (Berl) 188, 42-52. Epub 2006 Jul 19.

Fisk, J.D., Merry, H.R., Rockwood, K., 2003. Variations in case definition affect prevalence but not outcomes of mild cognitive impairment. Neurology 61, 1179-1184.

Flicker, C.S., Ferris, H., Reisberg, B., 1991. Mild cognitive impairment in the elderly: predictors of dementia. Neurology 41, 1006-1009.

Folstein, M.F., Folstein, S.E., McHugh, P.R., 1975. "Mini mental state”: a practical method for grading the cognitive state of patients for clinician. J. Psychiat Res, 12, 189-198.

Frisoni, G.B., Padovani, A., Wahlund, L.O., 2004. The predementia diagnosis of Alzheimer disease. Alzheimer Dis. Assoc. Disord. 18, 51-53.

Frisoni, G.B., Prestia, A., Rasser, P.E., Bonetti, M., Thompson, P.M., 2009. In vivo mapping of incremental cortical atrophy from incipient to overt Alzheimer's disease. J. Neurol. 256, 916-924. Epub 2009 Feb 28.

Frisoni, G.B., Testa, C., Zorzan, A., Sabattoli, F., Beltramello, A., Soininen, H., Laakso, M.P., 2002. Detection of gray matter loss in mild Alzheimer's disease with voxel-based morphometry. J. Neurol. Neurosurg. Psychiatry 73, 657-664.

Galluzzi, S., Cimaschi, L., Ferrucci, L., Frisoni, G.B., 2001. Mild cognitive impairment: clinical features and review of screening instruments. Aging (Milano) 13, $183-202$.

Gao, S., Hendrie, H.C., Hall, K.S., Hui, S., 1998. The relationships between age, sex, and the incidence of dementia and Alzheimer disease: a meta-analysis. Arch. Gen. Psychiatry 55, 809-815.

Goncalves, S.I., de Munck, J.C., Pouwels, P.J., Schoonhoven, R., Kuijer, J.P., Maurits, N.M., Hoogduin, J.M., Van Someren, E.J., Heethaar, R.M., Lopes da Silva, F.H., 2006. Correlating the alpha rhythm to BOLD using simultaneous EEG/fMRI: inter-subject variability. Neuroimage 30, 203-213. Epub 2005 Nov 14.

Helkala, E.L., Hanninen, T., Hallikainen, M., Kononen, M., Laakso, M.P., Hartikainen, P., Soininen, H., Partanen, J., Partanen, K., Vainio, P., Riekkinen, P., 1996. Slow-wave activity in the spectral analysis of the electroencephalogram and volumes of hippocampus in subgroups of Alzheimer's disease patients. Behav. Neurosci. 110, 1235-1243.

Hernández, J.L., Valdés, P., Biscay, R., Virués, T., Szava, S., Bosch, J., Riquenes, A. Clark, I., 1994. A global scale factor in brain topography. Int. J. Neurosci. 76 267-278.

Holschneider, D.P., Waite, J.J., Leuchter, A.F., Walton, N.Y., Scremin, O.U., 1999 Changes in electrocortical power and coherence in response to the selective cholinergic immunotoxin 192 IgG-saporin. Exp. Brain Res. 126, 270-280.

Huang, C., Wahlund, L.O., Dierks, T., Julin, P., Winblad, B., Jelic, V., 2000. Discrimination of Alzheimer's disease and mild cognitive impairment by equivalent EEG sources: a cross-sectional and longitudinal study. Clin. Neurophysiol. 11, 1961-1967.

Hughes, C.P., Berg, L., Danziger, W.L., Coben, L.A., Martin, R.L., 1982. A new clinical scale for the staging of dementia. Br. J. Psychiatry 140, 566-572.

Hughes, S.W., Crunelli, V., 2005. Thalamic mechanisms of EEG alpha rhythms and their pathological implications. Neuroscientist 11, 357-372. Review.

Jelic, V., Johansson, S.E., Almkvist, O., Shigeta, M., Julin, P., Nordberg, A., Winblad, B. Wahlund, L.O., 2000. Quantitative electroencephalography in mild cognitive impairment: longitudinal changes and possible prediction of Alzheimer's disease. Neurobiol. Aging 21, 533-540.

Jeong, J., 2004. EEG dynamics in patients with Alzheimer's disease. Clin. Neurophysiol. 115, 1490-1505.

Kassubek, J., Juengling, F.D., Hellwig, B., Spreer, J., Lücking, C.H., 2002. Thalamic gray matter changes in unilateral Parkinsonian resting tremor: a voxel-based morphometric analysis of 3-dimensional magnetic resonance imaging. Neurosci. Lett. 323, 29-32.

Kassubek, J., Juengling, F.D., Kioschies, T., Henkel, K., Karitzky, J., Kramer, B., Ecker, D., Andrich, J., Saft, C., Kraus, P., Aschoff, A.J., Ludolph, A.C., Landwehrmeyer, G.B. 2004. Topography of cerebral atrophy in early Huntington's disease: a voxe based morphometric MRI study. J. Neurol. Neurosurg. Psychiatry 75, 213-220.

Klimesch, W., 1996. Memory processes, brain oscillations and EEG synchronization. Int. J. Psychophysiol 24, 61-100.

Klimesch, W., 1999. EEG alpha and theta oscillations reflect cognitive and memory performance: a review and analysis. Brain Res. Rev. 29, 169-195.

Klimesch, W., Doppelmayr, M., Pachinger, T., Russegger, H., 1997. Event-related desynchronization in the alpha band and the processing of semantic information. Brain Res. Cogn. Brain Res. 6, 83-94.

Klimesch, W., Doppelmayr, M., Russegger, H., Pachinger, T., Schwaiger, J., 1998 Induced alpha band power changes in the human EEG and attention. Neurosci. Lett. 244, 73-76.

Koenig, T., Prichep, L., Dierks, T., Hubl, D., Wahlund, L.O., John, E.R., Jelic, V., 2005 Decreased EEG synchronization in Alzheimer's disease and mild cognitive impairment. Neurobiol. Aging 26, 165-171.

Korczyn, A.D., Halperin, I., 2009. Depression and dementia. J. Neurol. Sci. 283 139-142. Epub 2009 Apr 5.

Larrieu, S., Letenneur, L., Orgogozo, J.M., Fabrigoule, C., Amieva, H., Le Carret, N. Barberger-Gateau, P., Dartigues, J.F., 2002. Incidence and outcome of mild cognitive impairment in a population-based prospective cohort. Neurology 59 1594-1599.

Laufs, H., Kleinschmidt, A., Beyerle, A., Eger, E., Salek-Haddadi, A., Preibisch, C. Krakow, K., 2003. EEG-correlated fMRI of human alpha activity. Neuroimage 19, 1463-1476.

Lawton, M.P., Brodie, E.M., 1969. Assessment of older people: self maintaining and instrumental activity of daily living. J. Gerontol. 9, 179-186.

Lehmann, C., Koenig, T., Jelic, V., Prichep, L., John, R.E., Wahlund, L.O., Dodge, Y., Dierks, T., 2007. Application and comparison of classification algorithms for recognition of Alzheimer's disease in electrical brain activity (EEG). J. Neurosci. Methods 161, 342-350.

Leuchter, A.F., Spar, J.E., Walter, D.O., Weiner, H., 1987. Electroencephalographic spectra and coherence in the diagnosis of Alzheimer's-type and multi-infarct dementia. A pilot study. Arch. Gen. Psychiatry 44, 993-998.

Limon, A., Reyes-Ruiz, J.M., Miledi, R., 2011. GABAergic drugs and Alzheimer's disease. Future Med. Chem. 3, 149-153.

Lörincz, M.L., Crunelli, V., Hughes, S.W., 2008. Cellular dynamics of cholinergically induced alpha $(8-13 \mathrm{~Hz})$ rhythms in sensory thalamic nuclei in vitro. J. Neurosci. 28, 660-671.

Lorincz, M.L., Kékesi, K.A., Juhász, G., Crunelli, V., Hughes, S.W., 2009. Tempora framing of thalamic relay-mode firing by phasic inhibition during the alpha rhythm. Neuron 63, 683-696.

Mantini, D., Perrucci, M.G., Cugini, S., Ferretti, A., Romani, G.L., Del Gratta, C., 2007. Complete artifact removal for EEG recorded during continuous fMRI using independent component analysis. Neuroimage 34, 598-607. Epub 2006 Nov 16.

Mathewson, K.E., Gratton, G., Fabiani, M., Beck, D.M., Ro, T., 2009. To see or not to see: prestimulus alpha phase predicts visual awareness. J. Neurosci. 29, $2725-2732$

Mathewson, K.E., Lleras, A., Beck, D.M., Fabiani, M., Ro, T., Gratton, G., 2011. Pulsed out of awareness: EEG alpha oscillations represent a pulsed-inhibition of ongoing cortical processing. Front. Psychol. 2, 99. Epub 2011 May 19.

McKeith, I.G., Perry, E.K., Perry, R.H., 1999. Report of the second dementia with Lewy body international workshop: diagnosis and treatment. Consortiumon dementia with Lewy bodies. Neurology 53, 902-905.

McKhann, G., Drachman, D., Folstein, M., Katzman, R., Price, D., Stadlan, E.M., 1984 Clinical diagnosis of Alzheimer's disease: report of the NINCDS- ADRDA Work 
Group under the auspices of Department of Health and Human Services Task Force on Alzheimer's disease. Neurology 34, 939-944.

Mesulam, M.M., 1995. Cholinergic pathways and the ascending reticular activating system of the human brain. Ann. N.Y. Acad. Sci. 757, 169-179. No abstract available.

Mesulam, M., Shaw, P., Mash, D., Weintraub, S., 2004. Cholinergic nucleus basalis tauopathy emerges early in the aging-MCI-AD continuum. Ann. Neurol. 55, 815-828.

Missonnier, P., Gold, G., Herrmann, F.R., Fazio-Costa, L., Michel, J.P., Deiber, M.P., Michon, A., Giannakopoulos, P., 2006. Decreased theta event-related synchronization during working memory activation is associated with progressive mild cognitive impairment. Dement. Geriatr. Cogn. Disord. 22, 250-259.

Moretti, D.V., Babiloni, C., Binetti, G., Cassetta, E., Dal Forno, G., Ferreri, F., Ferri, R., Lanuzza, Bartolo., Miniussi, C., Nobili, F., Rodriguez, G., Salinari, S., Rossini, P.M., 2004. Individual analysis of EEG frequency and band power in mild Alzheimer's disease. Clin. Neurophysiol. 115, 299-308.

Moretti, D.V., Babiloni, F., Carducci, F., Cincotti, F., Remondini, E., Rossini, P.M., Salinari, S., Babiloni, C., 2003. Computerized processing of EEG-EOG-EMG artifacts for multicentirc studies in EEG oscillations and event-related potentials. Int. J. Pshycophysiol. 47, 199-216.

Moretti, D.V., Frisoni, G.B., Fracassi, C., Pievani, M., Geroldi, C., Binetti, G., Rossini, P.M., Zanetti, O., 2011. MCI patients' EEGs show group differences between those who progress and those who do not progress to AD. Neurobiol. Aging 32, 563-571.

Moretti, D.V., Miniussi, C., Frisoni, G.B., Geroldi, C., Zanetti, O., Binetti, G., Rossini, P.M., 2007. Hippocampal atrophy and EEG markers in subjects with mild cognitive impairment. Clin. Neurophysiol. 118, 2716-2729. Epub ahead of print.

Mowla, A., Mosavinasab, M., Haghshenas, H., Borhani Haghighi, A., 2007. Does serotonin augmentation have any effect on cognition and activities of daily living in Alzheimer's dementia? A double-blind, placebo-controlled clinical trial. J. Clin. Psychopharmacol. 27, 484-487.

Mummery, C.J., Patterson, K., Price, C.J., Ashburner, J., Frackowiak, R.S., Hodges, J.R., 2000. A voxel-based morphometry study of semantic dementia: relationship between temporal lobe atrophy and semantic memory. Ann. Neurol. 47, 36-45.

Nestor, P.J., Scheltens, P., Hodges, J.R., 2004. Advances in the early detection of Alzheimer's disease. Nat. Med. 10 Suppl, S34-S41.

Nishida, K., Yoshimura, M., Isotani, T., Yoshida, T., Kitaura, Y., Saito, A., Mii, H., Kato, M., Takekita, Y., Suwa, A., Morita, S., Kinoshita, T., 2011. Differences in quantitative EEG between frontotemporal dementia and Alzheimer's disease as revealed by LORETA. Clin. Neurophysiol. 122, 1718-1725. Epub 2011 Mar 10.

Nobili, L., Sannita, W.G., 1997. Cholinergic modulation, visual function and Alzheimer's dementia. Vis. Res. 37, 3559-3571.

Nuwer, M., 1997. Assessment of digital EEG, quantitative EEG and brain mapping: report of the American Clinical Neurophysiology Society. Neurology 49, $277-292$.

Ohnishi, T., Matsuda, H., Tabira, T., Asada, T., Uno, M., 2001. Changes in brain morphology in Alzheimer disease and normal ageing: is Alzheimer disease an exaggerated aging process? AJNR Am. J. Neuroradiol. 22, 1680-1685.

Orsini, A., Grossi, D., Capitani, E., Laiacona, M., Papagno, C., Vallar, G., 1987. Verbal and spatial immediate memory span: normative data from 1355 adults and 1112 children. Ital. J. Neurol. Sci. 8, 539-548.

Osipova, D., Rantanen, K., Ahveninen, J., Ylikoski, R., Häppölä, O., Strandberg, T., Pekkonen, E., 2006. Source estimation of spontaneous MEG oscillations in mild cognitive impairment. Neurosci. Lett. 405, 57-61.

Pascual-Marqui, R.D., Esslen, M., Kochi, K., Lehmann, D., 2002. Functional imaging with low resolution brain electromagnetic tomography (LORETA): a review. Methods findings Exp. Clin. Pharmacol. 24, 91-95.

Pascual-Marqui, R.D., Lehmann, D., Koenig, T., Kochi, K., Merlo, M.C., Hell, D., Koukkou, M., 1999. Low resolution brain electromagnetic tomography (LORETA) functional imaging in acute, neuroleptic-naive, first-episode, productive schizophrenia. Psychiatry Res. 90, 169-179.

Pascual-Marqui, R.D., Michel, C.M., 1994. LORETA (low resolution brain electromagnetic tomography): new authentic 3D functional images of the brain. ISBET Newsl. ISSN 5, 4-8.

Petersen, R.C., Doody, R., Kurz, A., Mohs, R.C., Morris, J.C., Rabins, P.V., Ritchie, K., Rossor, M., Thal, L., Winblad, B., 2001. Current concepts in mild cognitive impairment. Arch. Neurol. 58, 1985-1992.

Petersen, R.C., Smith, G.E., Ivnik, R.J., Tangalos, E.G., Schaid, S.N., Thibodeau, S.N., Kokmen, E., Waring, S.C., Kurland, L.T., 1995. Apolipoprotein E status as a predictor of the development of Alzheimer's disease in memory-impaired individuals. JAMA 273, 1274-1278.

Petersen, R.C., Smith, G.E., Waring, S.C., Ivnik, R.J., Kokmen, E., Tangelos, E.G., 1997. Aging, memory, and mild cognitive impairment. Int. Psychogeriatr. 9 (Suppl 1), 65-69.

Pinault, D., Deschênes, M., 1992. Muscarinic inhibition of reticular thalamic cells by basal forebrain neurones. Neuroreport 3, 1101-1104.

Pizzagalli, D.A., Oakes, T.R., Fox, A.S., 2004. Functional but not structural subgenual prefrontal cortex abnormalities in melancholia. Mol. Psychiatry 9, 393-405.

Ponomareva, N.V., Selesneva, N.D., Jarikov, G.A., 2003. EEG alterations in subjects at high familial risk for Alzheimer's disease. Neuropsychobiology 48, 152-159.
Portet, F., Ousset, P.J., Visser, P.J., Frisoni, G.B., Nobili, F., Scheltens, P., Vellas, B. Touchon, J., 2006. MCI Working Group of the European Consortium on Alzheimer's disease mild cognitive impairment $(\mathrm{MCI})$ in medical practice: a critica review of the concept and new diagnostic procedure. Report of the MC Working Group of the European Consortium on Alzheimer's disease. J. Neurol. Neurosurg. Psychiatry 77, 714-718. Epub 2006 Mar 20. Review.

Raven, 1965. Guide to Using Coloured Progressive Matrices. K Lewis, London UK.

Reitan, 1958. Validity of the trail making test as an indication of organic brain damage. Percept. Mot. Skill. 271-276.

Rey, A., 1958. Memorisation d'une serie de 15 mots en 5 repetitions. In: Rey, A. (Ed.), L'examen clinique en psychologie. Presses Universitaires de France, Paris.

Rey, A., 1968. Reattivo Della Figura Complessa Manuale. Organizzazioni Speciali Firenze.

Ricceri, L., Minghetti, L., Moles, A., Popoli, P., Confaloni, A., De Simone, R., Piscopo, P., Scattoni, M.L., di Luca, M., Calamandrei, G., 2004. Cognitive and neurological deficits induced by early and prolonged basal forebrain cholinergic hypofunction in rats. Exp. Neurol. 189, 162-172.

Rodriguez, G., Copello, F., Nobili, F., Vitali, P., Perego, G., Nobili, F., 1999a. EEG spectral profile to stage Alzheimer's disease. Clin. Neurophysiol. 110, 1831-1837.

Rodriguez, G., Nobili, F., Copello, F., Vitali, P., Gianelli, M.V., Taddei, G., Catsafados, E., Mariani, G., 1999b. 99mTc-HMPAO regional cerebral blood flow and quantitative electroencephalography in Alzheimer's disease: a correlative study. J. Nucl. Med. 40, 522-529.

Rodriguez, G., Nobili, F. Rocca, G. DeCarli, F., Gianelli, MV Rosadini, G., 1998 Quantitative electroencephalography and regional cerebral blood flow: discriminant analysis between Alzheimer's patients and healthy controls. Dement. Geriatr. Cogn. Disord. 9, 238-274.

Rogers, J., Webster, S., Lue, L.F., Brachova, L., Civin, W.H., Emmerling, M., Shivers, B. Walker, D., McGeer, P., 1996. Inflammation and Alzheimer's disease pathogenesis. Neurobiol. Aging 17, 681-686.

Roman, G.C., Tatemichi, T.K., Erkinjuntti, T., Cummings, J.L., Masdeu, J.C., Garcia, J.H, Amaducci, L., Orgogozo, J.M., Brun, A., Hofman, A., 1993. Vascular dementia: diagnostic criteria for research studies. Report of the NINDS-AIREN International Workshop. Neurology 43, 250-260.

Rombouts, S.A., Barkhof, F., Witter, M.P., Scheltens, P., 2000. Unbiased whole-brain analysis of gray matter loss in Alzheimer's disease. Neurosci. Lett. 285, 231-233.

Rosen, W.G., Terry, R.D., Fuld, P.A., Katzman, R., Peck, A., 1980. Pathological verification of ischemic score in differentiation of dementias. Ann. Neurol. 7, 486-488.

Rossini, P.M., Desiato, M.T., Lavaroni, F., Caramia, M.D., 1991. Brain excitability and electroencephalographic activation: non-invasive evaluation in healthy humans via transcranial magnetic stimulation. Brain Res. 567, 111-119.

Rossini, P.M., Rossi, S., Babiloni, C., Polich, J., 2007. Clinical neurophysiology of aging brain: from normal aging to neurodegeneration. Prog. Neurobiol. 83, 375-400. Review. Epub 2007 Aug 8.

Rubin, E.H., Morris, J.C., Grant, E.A., Vendegna, T., 1989. Very mild senile dementia of the Alzheimer type. I. Clinical assessment. Arch. Neurol. 46, 379-382.

Shattuck, D.W., Mirza, M., Adisetiyo, V., Hojatkashani, C., Salamon, G., Narr, K.L., Poldrack, R.A., Bilder, R.M., Toga, A.W., 2008. Construction of a 3D probabilistic atlas of human brain structures. Neuroimage 39, 1064-1080.

Scheltens, P., Fox, N., Barkhof, F., De Carli, C., 2002. Structural magnetic resonance imaging in the practical assessment of dementia: beyond exclusion. Lancet Neurol. 1, 13-21.

Shulman, K.I., Gold, D.P., Cohen, C.A., Zucchero, C.A., 1993. Clock drawing and dementia in the community: a longitudinal study. Int. J. Geriatr. Psychiatry 8 , 487-496.

Sloan, E.P., Fenton, G.W., Kennedy, N.S.J., MacLennan, J.M., 1995. Electroencephalography and single photon emission computed tomography in dementia: a comparative study. Psychol. Med. 25, 631-638.

Small, G.W., La Rue, A., Komo, S., Kaplan, A., Mandelkern, M.A., 1995. Predictors of cognitive change in middle-aged and older adults with memory loss. Am. J Psychiatry 152, 1757-1764.

Spinnler, H., Tognoni, G., 1987. Standardizzazione e taratura italiana di test neuropsicologici. Ital. J. Neurol. Sci. suppl 8, 1-120.

Steriade, M., Llinas, R.R., 1988. The functional states of the thalamus and the associated neuronal interplay. Physiol. Rev. 68, 649-742.

Steriade, M., 2003. Cerebello-cerebral interactions during states of vigilance. Cerebellum 2, 82-83.

Strijers, R.L., Scheltens, P., Jonkman, E.J., de Rijke, W., Hooijer, C., Jonker, C., 1997. Diagnosing Alzheimer's disease in community-dwelling elderly: a comparison of EEG and MRI. Dement. Geriatr. Cogn. Disord. 8, 198-202.

Talairach, J., Tournoux, P., 1988. Co-planar Stereotaxic Atlas of the Human Brain. Thieme, Stuttgart.

Tanaka, Y., Hanyu, H., Sakurai, H., Takasaki, M., Abe, K., 2003. Atrophy of the substantia innominata on magnetic resonance imaging predicts response to donepezil treatment in Alzheimer's disease patients. Dement. Geriatr. Cogn. Disord. 16, 119-125.

Teipel, S.J., Flatz, W.H., Heinsen, H., Bokde, A.L., Schoenberg, S.O., Stockel, S., Dietrich, O., Reiser, M.F., Moller, H.J., Hampel, H., 2005. Measurement of basal forebrain atrophy in Alzheimer's disease using MRI. Brain 128 (Pt 11) 2626-2644. 
Testa, C., Laakso, M.P., Sabattoli, F., Rossi, R., Beltramello, A., Soininen, H., Frisoni, G.B., 2004. A comparison between the accuracy of voxel-based morphometry and hippocampal volumetry in Alzheimer's disease. J. Magn. Reson. Imaging 19, 274-282.

Valdès, P., Picton, T.W., Trujillo, N., Bosch, J., Aubert, E., Riera, J., 1998. Constraining EEG-MEG source imaging with statistical neuroanatomy. Neuroimage 4, 635.

Van der Hiele, K., Vein, A.A., Reijntjes, R.H., Westendorp, R.G., Bollen, E.L., van Buchem, M.A., van Dijk, J.G., Middelkoop, H.A., 2007. EEG correlates in the spectrum of cognitive decline. Clin. Neurophysiol. 118, 1931-1939. Epub 2007 Jun 28.

Varela, F.J., Toro, A., John, E.R., Schwartz, E.L., 1981. Perceptual framing and cortical alpha rhythm. Neuropsychologia 19, 675-686.

Wolf, H., Jelic, V., Gertz, H.J., Nordberg, A., Julin, P., Wahlund, L.O., 2003. A critical discussion of the role of neuroimaging in mild cognitive impairment. Acta Neurol. Scand. 107 (Suppl 179), 52-76.
Yesavage, J.A., Brink, T.L., Rose, T.L., Lum, O., Huang, V., Adey, M., Leirer, V.O., 19821983. Development and validation of a geriatric depression screening scale: a preliminary report. J. Psychiatr. Res. 17, 37-49.

Zhang, Y., Brady, M., Smith, S., 2001. Segmentation of brain MR images through a hidden Markov random field model and the expectation-maximization algorithm. IEEE Trans. Med. Imaging 20, 45-57.

Zappoli, R., Versari, A., Paganini, M., Arnetoli, G., Muscas, G.C., Gangemi, P.F. Arneodo, M.G., Poggiolini, D., Zappoli, F., Battaglia, A., 1995. Brain electrical activity (quantitative EEG and bit-mapping neurocognitive CNV components), psychometrics and clinical findings in presenile subjects with initial mild cognitive decline or probable Alzheimer-type dementia. Ital. J. Neurol. Sci. 16 341-376. Review.

Zaudig, M., 1992. A new systematic method of measurement and diagnosis of "mild cognitive impairment" and dementia according to ICD-10 and DSM-III-R criteria. Int. Psychogeriatr 4 (Suppl 2), 203-219. 